This item was submitted to Loughborough's Research Repository by the author.

Items in Figshare are protected by copyright, with all rights reserved, unless otherwise indicated.

\title{
Characterisation, control, and energy management of electrified turbocharged diesel engines
}

\section{PLEASE CITE THE PUBLISHED VERSION}

http://dx.doi.org/10.1016/j.enconman.2016.12.033

\section{PUBLISHER}

(C) Elsevier

\section{VERSION}

AM (Accepted Manuscript)

\section{PUBLISHER STATEMENT}

This work is made available according to the conditions of the Creative Commons Attribution-NonCommercialNoDerivatives 4.0 International (CC BY-NC-ND 4.0) licence. Full details of this licence are available at: https://creativecommons.org/licenses/by-nc-nd/4.0/

\section{LICENCE}

CC BY-NC-ND 4.0

\section{REPOSITORY RECORD}

Zhao, Dezong, Edward Winward, Zhijia Yang, Richard Stobart, and Thomas Steffen. 2017. "Characterisation, Control, and Energy Management of Electrified Turbocharged Diesel Engines". figshare. https://hdl.handle.net/2134/24350. 


\title{
Characterisation, control, and energy management of electrified turbocharged diesel engines
}

\author{
Dezong Zhao ${ }^{\mathrm{a}, *}$, Edward Winward ${ }^{\mathrm{b}}$, Zhijia Yang ${ }^{\mathrm{a}}$, Richard Stobart ${ }^{\mathrm{a}}$, Thomas \\ Steffen $^{\mathrm{a}}$ \\ ${ }^{a}$ Department of Aeronautical and Automotive Engineering, Loughborough University, \\ Loughborough LE11 3TU, UK \\ ${ }^{b}$ Energy and Transportation Research, Caterpillar Inc., Peterborough PE1 5FQ, UK
}

\begin{abstract}
The electrification of engine components offers significant opportunities for fuel efficiency improvements. The electrified turbocharger is one of the most attractive options since it recovers part of the engine exhaust gas mechanical energy to assist boosting. Therefore, the engine can be downsized through improved transient responsiveness. In the electrified turbocharger, an electric machine is mounted on the turbine shaft and changes the air system dynamics, so characterisation of the new layout is essential. A systematic control solution is required to manage energy flows in the hybrid system. In this paper, a framework for characterisation, control, and energy management for an electrified turbocharged diesel engine is proposed. The impacts of the electric machine on fuel economy and air system variables are analysed. Based on the characterisation, a two-level control structure is proposed. A real-time energy management strategy is employed as the supervisory level controller to generate the optimal values of critical variables, while a model-based multi-variable controller is designed as the low level controller to track the values. The two controllers work together in a cascade to address both fuel economy optimisation and battery state-of-charge maintenance. The proposed control strategy is validated on a high fidelity physical engine model. The tracking performance shows the proposed framework is a promising solution in regulating the behavior of electrified engines.
\end{abstract}

Keywords:

\footnotetext{
${ }^{*}$ Corresponding author

Email address: d. zhao@ lboro.ac.uk (Dezong Zhao )
} 
Electrified turbocharged diesel engines, energy management, real-time optimisation, multi-variable control 


\section{Highlights}

- A real-time energy management framework for electrified engines is proposed.

- A multi-variable robust controller is designed.

- Characterisation on the air system of electrified diesel engines is given.

- Reliable for engine downsizing because of the promising transient performance.

\section{Introduction}

Fuel saving in the transportation is a global critical issue. The transportation sector is the second largest source of greenhouse gas generation and consumes a half of crude oil. In most developed countries, a clear target in improving fuel efficiency of the vehicles has been made by legislation and policies [1]. Engine downsizing offers promising fuel economy improvements by the reduction of friction, thermal losses, and mass [2]. It allows the engine to run in a more fuel-efficient region [3]. The reduced displacement of the downsized engine can be compensated by injecting more fresh air into the cylinder for better combustion [4]. Better air delivery is feasible now by turbocharging, where the state-of-the-art technology is the electrified turbocharger [5]. In the electrified turbocharger, an extra-high speed electric machine (EM) is mounted on the turbine shaft. In periods of speed acceleration or load acceptance, the EM can run as a motor to augment the turbine power to the compressor and, therefore, increase the flow fresh air from the compressor to improve engine performance. This is achieved through either increased availability of combustion air or a reduction in pre-turbine back pressure. In specific engine operating regions, the fuel economy benefit of using an electrified turbocharger is up to $10 \%$ [6]. Compared with feeding energy to the crankshaft, the electrified turbocharger is more efficient in improving fuel efficiency for the mechanical losses are reduced [7]. The EM can also run as a generator when exhaust gas power excess the requirement on the compressor side. Several other waste energy recovery technologies are also being developed, where the typical solutions are Organic Rankine Cycle (ORC) and thermal electric generator (TEG). As for the ORC, the major obstacles in installing it on ground vehicles are its high cost and systems complexity [8]. As for the TEG, breakthroughs on the bottlenecks of expensive materials and low energy conversion efficiency are still being expected [9]. The electrified turbochargers gains their popularity since it is easy to assemble and more cost effective [10]. 
Diesel engines are predominantly used in heavy-duty vehicles and therefore their downsizing would be essential for reducing total fuel consumption [11]. The electrified turbocharger offers a promising solution for the effective air charging of diesel engines. Several prototypes are being developed by leading diesel engine and turbocharger suppliers. In 2003, Caterpillar demonstrated the fuel economy benefit of using the electric turbocompounding on heavy-duty engines [12]. In 2005, Honeywell reported the improvements of fuel economy and transient response using the electric boosting system [13]. In 2006, Mitsubishi developed a hybrid turbo that achieves better combustion, purer exhaust gas, and improved torque response [14]. In academic pioneer works, theoretical analysis and experimental evaluations on the potential of using an electrified turbocharger in fuel economy benefit, exhaust emissions reduction, and torque enhancement are all investigated. The theoretical analysis is given in [15], where an optimisation problem is formulated and solved numerically. The experimental evaluations are given in [16], where the turbo-lag reduction in several typical driving cycles are analysed. The comparison of the transient response improvement using an electrified turbocharger and using an electric turbocompounding is given in [17]. The electrified turbocharger with a different configuration, such as a two-stage electrified turbocharger, is investigated in [18]. In 2014, a consortium led by Caterpillar developed an entirely new electrified turbocharger for heavy-duty diesel engines, called the electric turbo assist (ETA). The characterisation of the ETA has been fulfilled through both simulations and experiments. In [19], the potential of the ETA to reduce fuel consumption by both engine downspeeding and exhaust energy recovery is elaborated in steady states via simulations. In [20], the simulation studies are generalised to transient conditions. In experiments, the mathematical modeling is investigated in [21]. Furthermore, an efficiency mapping work is given in [22]. The improvements in engine energy efficiency and transient response in experiments are covered in [23]. The key issue in the success of an electrified turbocharged diesel engine (ETDE) is online management of energy flows. First of all, the timing control of the EM to work in the generating mode or the motoring mode is necessary. Furthermore, how much power should be applied or extracted needs to be known precisely. Finally at the system level, how the EM works in co-operation with other actuators is fundamental. The control of an electrified turbocharger is challenging because of couplings among different control loops. In modern turbocharged diesel engines, the VGT reduces fuel consumption and, together with exhaust gas recirculation (EGR), enables a reduction in exhaust emissions, particularly nitrogen oxides $\left(\mathrm{NO}_{\mathrm{x}}\right)$. VGT and EGR work together to meet the desired burnt gas fraction and air-fuel ratio. The VGT loop and EGR 
loop are strongly coupled because the actuators are both in the exhaust gas flow. In an ETDE, the coupling also indicates that the EM affects the exhaust manifold behaviour.

In an ETDE, the selection of control variables is the primary task, for a proper set of control variables can reveal critical engine dynamics [24]. In conventional turbocharged diesel engines, the boost pressure and fresh air flow are normally employed for air system control, with the inputs of VGT opening and EGR opening [25]. Many control methods have been demonstrated on turbocharged diesel engines, which can be mainly categorized into decentralized control and 2-input 2-output (2I2O) centralized control. One of the most influential control methods in decentralized control is linear parameter-varying control [26]. Another typical solution is sliding mode control [27]. On the other side, the most important centralized control method is model predictive control [28]. Recently, fuzzy control has also attracted wide interests[29]. In the ETDE, the EM power is an extra degree of freedom in air system regulation, and therefore, an extra control variable is required to be introduced to reveal the energy balance between fuel and electricity. A 3-input 3-output (3I3O) control structure would be established based on the three actuators and three selected control variables. Some pioneer works on the control of an ETDE have been contributed by the authors. In [30], a 3I3O explicit model predictive control solution is presented. In [31], a 3I3O decoupling control method is demonstrated. In [32], a loop-shaping-based 3I3O robust control method is introduced. However, the general method for selecting control variables is still untouched. This crucial work is regarded as the characterisation of the new layout engine.

After the engine characterisation, the fuel economy optimisation is transformed into the generation and tracking of the optimal values for selected control variables. The choice of these values delivers the optimal performance of the ETDE. The core problem to be highlighted is to identify the best values of all three control variables [33]. This is of practical importance and is common in diesel engines, regardless of the controller type. For the sustainable usage of on-board battery, the maintenance of the battery state-of-charge (SOC) is a critical constraint to be considered. A suitable control and optimisation structure for the ETDE is still to be found. In [34], the actuators are controlled in a rule-based way. However neither the principle of selecting control variables nor the handling of battery SOC constraint has been addressed. This paper presents an attempt to address this gap. The main contributions are:

1. A control-oriented characterisation on the air system of the ETDE is pro- 
posed. From this, a clear guideline for the selection of control variables for the ETDE follows.

2. A hierarchical structure for energy management and control is presented. On the supervisory level, the optimal values of control variables are computed to distribute energy flows in the optimal way. On the low level, a multi-input multi-output (MIMO) controller is designed to implement the optimal energy flow distribution.

3. A real-time energy flow management strategy is designed as the supervisory level controller to guarantee the optimisation of fuel economy while keeping the sustainable battery usage.

4. A model-based non-smooth robust controller is designed as the low level controller to regulate the air system dynamics and to address the internal couplings among loops.

To verify the effectiveness of the proposed framework, cross-platform simulations have been carried out on a high fidelity physical plant model built in Dynasty, a proprietary multi physics simulation software package developed by Caterpillar. The engine manifolds are modeled as one-dimensional modules, such that the pulsations caused by the engine actuators operation can be captured precisely. To accurately simulate the transient performance, the energy transferred from each cylinder to the turbocharger was modeled separately.

The paper is organized as follows. Following the introduction in section 1, the control problem is formulated in section 2. The ETDE system description is given in section 3, and the control-oriented system characterisation is given in section 4 . The low level controller design is presented in section 5, and the supervisory level controller in section 6. Physical simulation results are demonstrated in section 7, followed by conclusions in section 8 .

\section{Problem Formulation}

The framework of characterisation, control, and optimisation is to be built as Fig. 1, while the task of each level is introduced in the following.

\subsection{Characterisation}

In the system characterisation, the impacts of EM on fuel economy and air system variables are analysed. Based on these analyses, the control variables in 


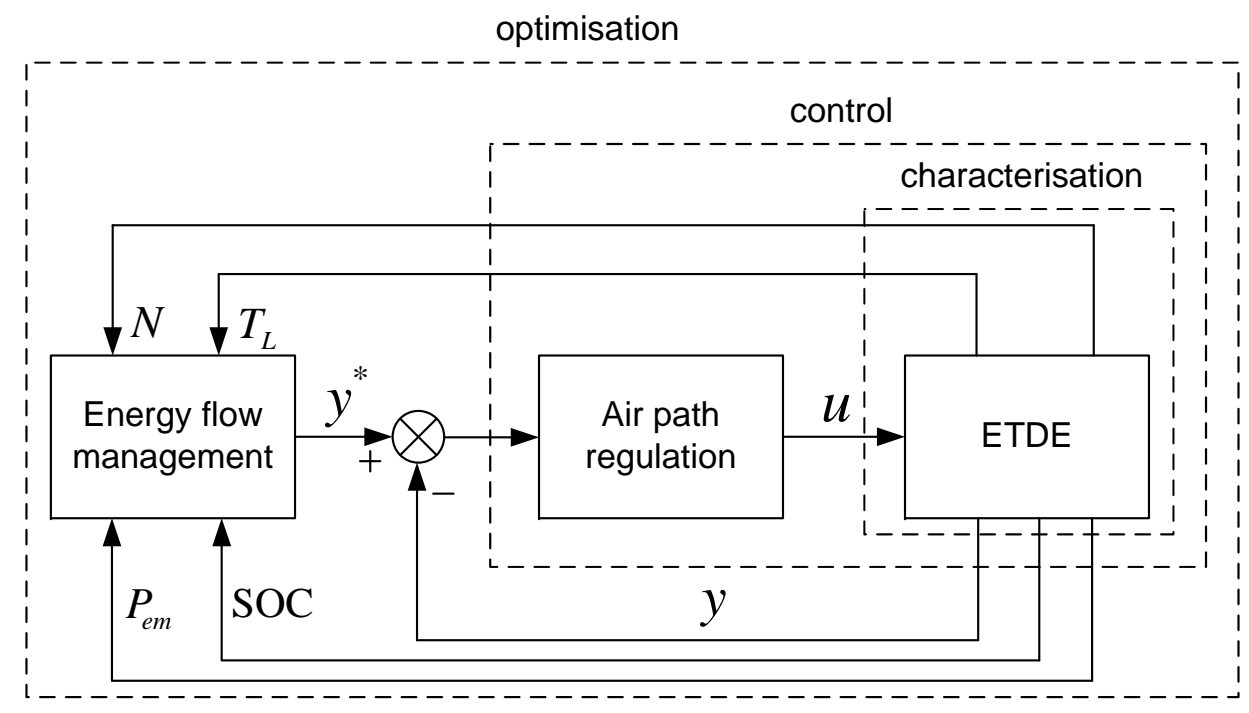

Figure 1: On-line energy management diagram of the ETDE

the new layout are to be selected, which use the additional degree of freedom introduced by the EM actuator for best effect. The selected variables cannot be strongly coupled for independent control on each of them. Based on the characterisation, the air system variables are tuned in two levels for online optimisation: (1) on the low level, the air system variables are controlled to track their setpoints; and (2) on the high level, the setpoints of variables are optimised and exported to minimize fuel consumption.

\subsection{Control}

Air system regulation is to track the computed setpoints $y^{*}$. Because the air system is highly nonlinear, it is challenging to build an effective global control strategy that covers all possible operating regions. Developing piecewise-linear controllers at different operating points is a feasible approach, where the operating points are determined by the independent variables of engine speed and load [35]. The entire engine operating region is segregated into several subzones and the identified model at the operating point is effective in the located subzone. The number of subzones depends on the required precision of the identified model. The engine air system behaviour is also nonlinear with the actuators position. In the ETDE air system, three actuators work together, resulting in too many possible combinations if the controller gains are scheduled over the actuator positions. 


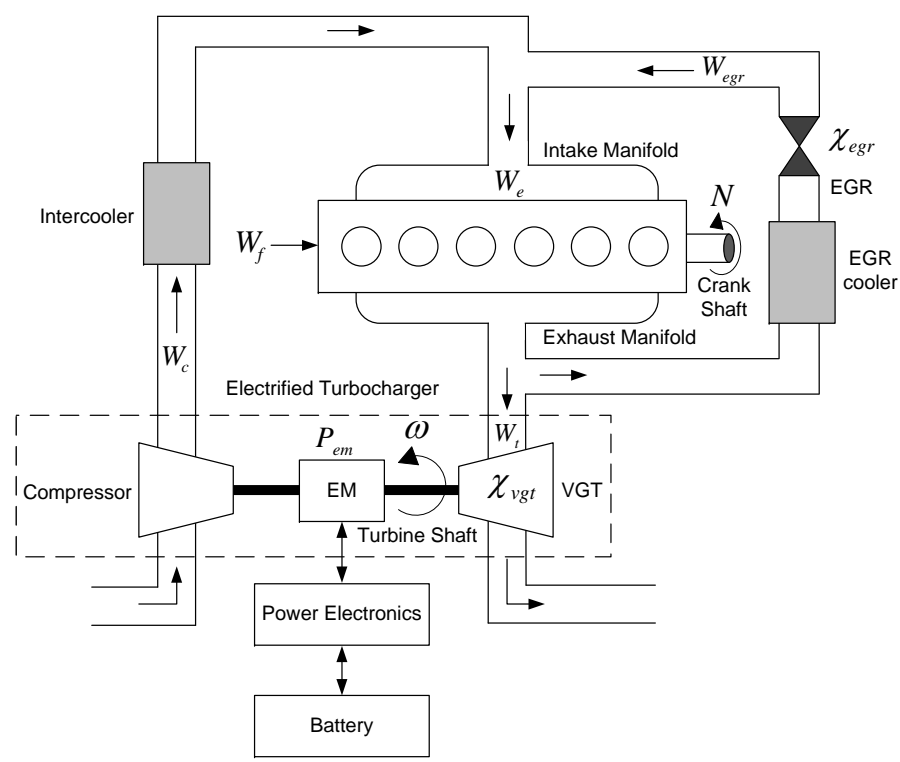

Figure 2: Electrified turbocharged diesel engine

Alternatively, a unified robust controller at a single operating point is expected to be designed.

\subsection{Optimisation}

Energy flow management is to minimize the total energy consumption of the ETDE in real-time. The burnt fuel power of the engine is

$$
P_{a}=H_{\mathrm{LHV}} W_{f},
$$

where $H_{\mathrm{LHV}}$ is the lower heating value of the fuel. In an ETDE, the instantaneous equivalent consumed power is given by

$$
P_{e q}=P_{a}+s(\mathrm{SOC}) P_{b},
$$

where $P_{b}$ is the battery power, and $s(\mathrm{SOC})$ is an equivalent factor to perform as a necessary penalty on battery SOC deviation.

The cost function is selected as $P_{e q}$ to quantify the equivalent consumed power

$$
J\left(y^{*}\right)=P_{e q},
$$

and therefore, the on-line optimisation problem is formulated as

$$
\begin{array}{ll}
\underset{y^{*}}{\operatorname{minimize}}: & J\left(y^{*}\right), \\
\text { subject to : } & y_{\min }^{*} \leq y^{*} \leq y_{\max }^{*},
\end{array}
$$


where the limits on $y^{*}$ denote the permissible range of the setpoints set. Considering the constraints on the computational efficiency in real-time engine control, it is more reasonable to generate $y^{*}$ from a lookup table way, rather than solving an optimal problem on-line.

\section{System Description}

The schematic of an ETDE is illustrated in Fig. 2, while its variables and related parameters are defined in Table 1. The VGT, EM, and compressor are mounted on the same turbine shaft, comprising the electrified turbocharger. The turbine blades accelerate the turbine shaft to boost fresh air injection through the compressor. The EGR loop feeds part of the burnt gas back to the intake manifold to dilute the fresh air. The mixed air and gas are pumped into the cylinders. In the electrified turbocharger, the EM can assist the turbine shaft when it works in the motoring mode, and can extract energy from turbine shaft to battery in the generating mode.

The engine is a 6-cylinder, 7.01-Litre heavy-duty off-highway engine equipped with a common rail fuel system. The engine produces up to $205 \mathrm{~kW}$ at rated speed of $2200 \mathrm{rpm}$ with a peak torque of $1257 \mathrm{Nm}$ at $1400 \mathrm{rpm}$. An electrical turbocharger with the rated power of $5 \mathrm{~kW}$ is fitted to the engine for the purposes of this work. The battery capacity is set as $0.03 \mathrm{kWh}$ considering the balance between usage flexibility and cost. The EM is represented as a map-based model, whose maximum motoring power and generating power are found from a twodimensional map, with the inputs of $\omega$ and power electronics controller setting.

Based on the conservation laws of mass and energy, the engine model is represented by the pressure changes in the intake and exhaust manifolds, and by the change on the turbine speed:

$$
\begin{aligned}
\dot{p}_{i n} & =\frac{R_{g} \gamma}{V_{i n}}\left(W_{c} T_{c}+W_{e g r} T_{e g r}-W_{e} T_{i n}-\frac{\dot{Q}_{1}}{c_{p}}\right), \\
\dot{p}_{e x h} & =\frac{R_{g} \gamma}{V_{e x h}}\left(\left(W_{e}+W_{f}\right) T_{g a s}-\left(W_{e g r}+W_{t}\right) T_{e x h}-\frac{\dot{Q}_{2}}{c_{p}}\right), \\
\dot{\omega} & =\frac{1}{J \omega}\left(\eta_{m}\left(P_{t}+P_{e m}\right)-P_{c}\right) .
\end{aligned}
$$

$\dot{Q}_{1}$ and $\dot{Q}_{2}$ indicate the heat losses in the intake and exhaust manifolds, respectively [36]. The temperatures are modeled as nonlinear functions, while the coefficients are determined by the materials and geometry of different components 
Table 1: Nomenclature

\begin{tabular}{lll}
\hline Variable & Description & $\mathrm{Unit}$ \\
\hline$N$ & Engine speed & $\mathrm{rpm}$ \\
$T_{L}$ & Engine load & $\mathrm{Nm}$ \\
$W_{f}$ & Engine fuelling rate & $\mathrm{kg} / \mathrm{s}$ \\
$W_{e}$ & Egnine total mass flow rate & $\mathrm{kg} / \mathrm{s}$ \\
$W_{c}$ & Compressor air mass flow rate & $\mathrm{kg} / \mathrm{s}$ \\
$W_{e g r}$ & EGR mass flow rate & $\mathrm{kg} / \mathrm{s}$ \\
$W_{t}$ & Turbine gas mass flow rate & $\mathrm{kg} / \mathrm{s}$ \\
$P_{c}$ & Compressor power & $\mathrm{kW}$ \\
$P_{t}$ & Turbine power & $\mathrm{kW}$ \\
$P_{e m}$ & EM power & $\mathrm{kW}$ \\
$p_{i n}$ & Intake manifold pressure & $\mathrm{kPa}$ \\
$p_{e x h}$ & Exhaust manifold pressure & $\mathrm{kPa}$ \\
$T_{i n}$ & Intake manifold temperature & $\mathrm{K}$ \\
$T_{e x h}$ & Exhaust manifold temperature & $\mathrm{K}$ \\
$T_{e g r}$ & Mass flow temperature at the EGR outlet & $\mathrm{K}$ \\
$T_{c}$ & Air temperature at the compressor outlet & $\mathrm{K}$ \\
$T_{g a s}$ & Exhaust gas temperature from the engine & $\mathrm{K}$ \\
$V_{i n}$ & Intake manifold volume & $\mathrm{m} 3$ \\
$V_{e x h}$ & Exhaust manifold volume & $\mathrm{m}{ }^{3}$ \\
$\omega$ & Turbine speed & $\mathrm{rpm}$ \\
$J$ & Turbine shaft moment of inertia & $\mathrm{kg} / \mathrm{s}^{2}$ \\
$\eta_{c}$ & Compressor isentropic efficiency & - \\
$\eta_{v}$ & Volumetric efficiency & - \\
$\eta_{m}$ & Turbocharger mechanical efficiency & - \\
$\chi_{e g r}$ & EGR valve opening & - \\
$\chi_{v g t}$ & VGT vane opening & - \\
$c_{p}$ & Specific heat at constant pressure, 1.01 & $\mathrm{~kJ} /(\mathrm{kgK})$ \\
$c_{v}$ & Specific heat at constant volume, 0.718 & $\mathrm{~kJ} /(\mathrm{kgK})$ \\
$R_{g}$ & Specific gas constant, $c_{p}-c_{v}$ & $\mathrm{~kJ} /(\mathrm{kgK})$ \\
$\gamma$ & Specific heat ratio, $c_{p} / c_{v}$ & - \\
\hline & & \\
\hline & & \\
\hline
\end{tabular}


to capture the impacts of heat transfer on engine behaviour. The mechanical efficiency $\eta_{m}$ is introduced to quantify the bearing power losses on turbine shaft and windage losses in the EM. Strong nonlinearities exist in the air system for the mass flow exchanges among the EGR, turbine, compressor, and manifolds, together with the powers generated by the turbine and consumed by the compressor. The mass flow rates and powers can be expressed in implicit forms:

$$
\begin{array}{ll}
W_{\text {egr }}=f\left(p_{\text {in }}, p_{\text {exh }}, \chi_{\text {egr }}\right), & W_{e}=f\left(p_{\text {in }}, T_{i n}, \eta_{v}, N\right), \\
W_{t}=f\left(p_{\text {exh }}, T_{\text {exh }}, \chi_{\text {vgt }}\right), & W_{c}=f\left(p_{\text {in }}, \omega\right), \\
P_{t}=f\left(W_{t}, T_{\text {exh }}, p_{\text {exh }}, \eta_{t}\right), & P_{c}=f\left(W_{c}, p_{\text {in }}, \eta_{c}\right) .
\end{array}
$$

The EGR loop mass flow rate is modeled as the standard orifice equation, while the engine total mass flow rate is modeled by the speed-density equation [37]. Turbine mass flow rate and air mass flow rate are modeled as nonlinear functions with respect to the efficiency $\eta_{t}$ and $\eta_{c}$, which are generated by steady state characterisation maps provided by the turbocharger supplier.

In the proposed research, a switched reluctance motor (SRM) is employed as the ETA since there is no winding on the rotor. The simple structure grants the SRM high rotor temperature capability. The SRM has no concern about the high cost of rare-earth materials.

\section{System Characterisation}

The system characterisation will analyse the impacts of ETA on fuel economy and air system variables, to underpin the selection of critical control variables.

\subsection{Analysis of ETA on Fuel Economy}

Table 2: Settings on the actuator actions in calibration tests

\begin{tabular}{|l|l|l|l|}
\hline \multirow{2}{*}{ Settings } & \multicolumn{3}{|c|}{ Actuators } \\
\cline { 2 - 4 } & $\chi_{\text {vgt }}$ & $P_{\text {em }}$ & $\chi_{\text {egr }}$ \\
\hline Minimum value & 0.1 & $-5 \mathrm{~kW}$ & 0 \\
\hline Maximum value & 0.5 & $5 \mathrm{~kW}$ & 0.3 \\
\hline Step & 0.1 & $2.5 \mathrm{~kW}$ & 0.1 \\
\hline
\end{tabular}

The engine brake specific fuel consumption would decline when ETA runs in the motoring mode and would increase when ETA runs in the generating mode. To 

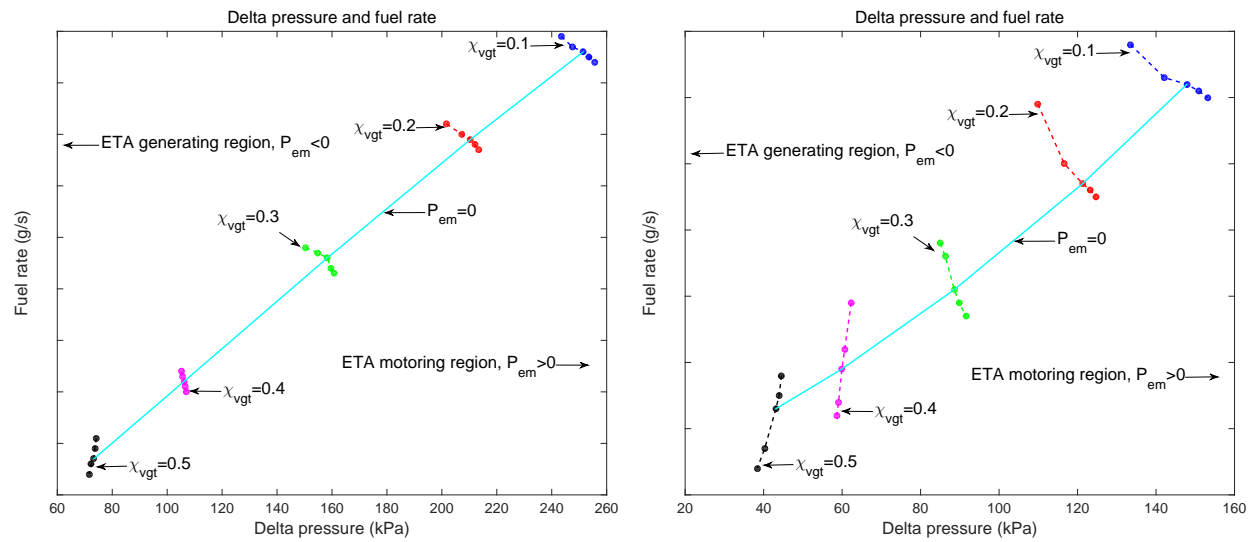

(a) $\Delta p$ and $W_{f}$ at no EGR

(b) $\Delta p$ and $W_{f}$ at $\chi_{\text {egr }}=0.3$
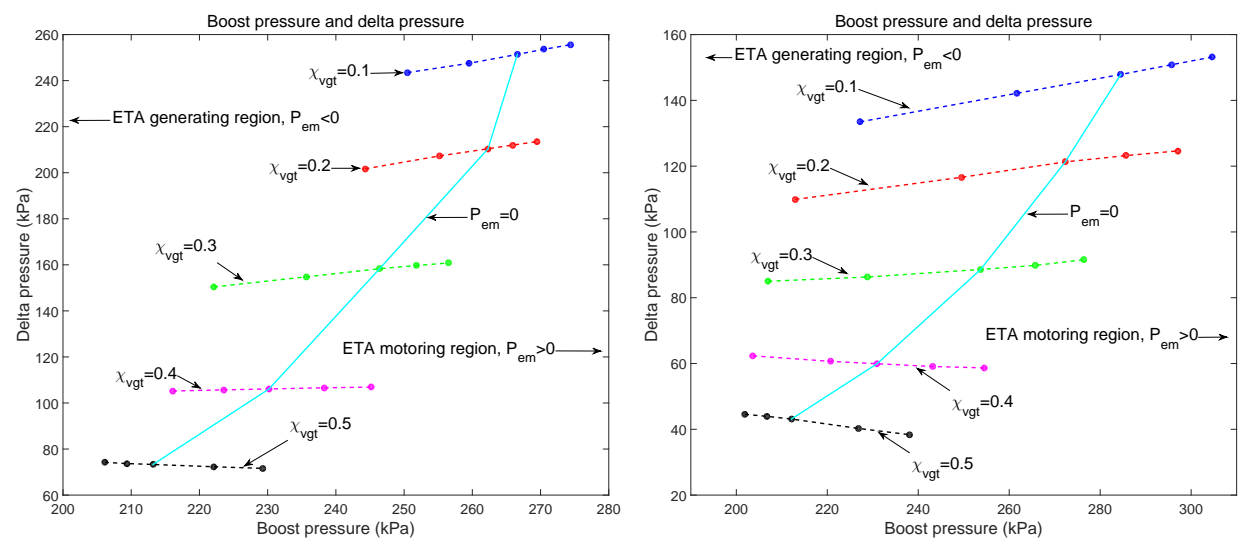

(c) $p_{i n}$ and $\Delta p$ at no EGR

(d) $p_{i n}$ and $\Delta p$ at $\chi_{e g r}=0.3$

Figure 3: Relation between $\Delta p$, fuel rate, and boost pressure

analyse the impact of ETA on the engine fuel economy, a group of calibration tests have been made on a 7.01-Litre heavy-duty ETDE at $1800 \mathrm{rpm}$ at approximately $60 \%$ load. The actuator actions are kept as constants in a single test, and their settings are shown in Table 2 . Two groups of calibration at $\chi_{\text {egr }}=0$ and $\chi_{\text {egr }}=$ 0.3 are elaborated for illustration.

In both Fig. 3(a) and Fig. 3(b), when $\chi_{v g t}$ and $\chi_{\text {egr }}$ are fixed, the fuel rate declines when $P_{e m}$ increases, indicating the fuel efficiency improves because of the ETA motoring. In the ETA motoring mode, the air-fuel-ratio is increased with no requirement for more turbine power, which leads to a reduction on engine pumping losses and therefore, the fuel efficiency is improved. When $\chi_{v g t}$ closes 
from 0.5 to 0.1 with fixed $P_{e m}$ and $\chi_{e g r}$, more penalties on pumping efficiency and mechanical efficiency are suffered. As a result, the fuel efficiency is reduced. In the process of $\chi_{v g t}$ closing, the turbine shaft spins faster and therefore more fresh air is boosted into the engine. To keep a fair air-fuel-ratio, more fuel is required to be burned. As a consequence, the fuel rate increases. Similar phenomena can be observed when $\chi_{e g r}$ varies with fixed $\chi_{v g t}$ and $P_{e m}$. When $\chi_{e g r}$ increases, more exhaust gas is recirculated into the intake manifold and reduces the amount of air. Accordingly, the fuel rate reduces to keep a reasonable air-fuel-ratio.

The difference between the boost pressure and exhaust pressure is defined as

$$
\Delta p=p_{\text {exh }}-p_{\text {in }} .
$$

The impact of the actuator actions can be revealed by the variations on $\Delta p$. At a specified boost pressure level, the fuel rate is determined by the $\Delta p$ value. Since the setpoint of $p_{i n}$ is normally generated by the engine control unit (ECU), the fuel rate of an ETDE can be regulated in closed-loop control by tuning the setpoint of $\Delta p$.

Fig. 3(c) and Fig. 3(d) illustrate the relation between $\Delta p, p_{i n}$ and actuator actions. As $\chi_{v g t}$ closes from 0.5 to 0.1 with fixed $P_{e m}$, both $p_{i n}$ and $p_{e x h}$ increase, as well as the condition when $P_{e m}$ increases with the fixed $\chi_{v g t}$. When ETA switches from the generating mode to the motoring mode, $\Delta p$ increases slightly at low $\chi_{v g t}$ opening (towards close), and drops slightly at high $\chi_{v g t}$ opening (towards open). This phenomenon is because the expansion ratio of the turbine varies with different $\chi_{v g t}$ values.

\subsection{Analysis of ETA on Air System Variables}

The key to reducing exhaust emissions in terms of $\mathrm{NO}_{\mathrm{x}}$ and particulate matters (PM) is keeping rational values of air-fuel ratio and EGR fraction, which can be obtained from the independent variables $W_{c}$ and $W_{\text {egr }}$. Equally, the independent variables can also be replaced by $p_{i n}$ and $W_{\text {egr }}$. However, due to the introduction of ETA in the ETDE, controlling only $p_{i n}$ and $W_{\text {egr }}$ is not enough. A further performance variable in the exhaust manifold has to be considered. In the available literature, explicit principles for selecting control variables of an ETDE have not been found.

Fig. 4(a) and Fig. 4(b) show the strong coupling between $p_{i n}$ and $\omega$ in the setting of $\chi_{\text {egr }}=0$ and $\chi_{\text {egr }}=0.3$, respectively. In both conditions, $\omega$ behaves as a polynomial function with $p_{i n}$. The causality logics can be explained by physics. The enthalpy in the exhaust gas speeds up the turbocharger, which is a slow process. The rotational motion of the compressor blades then transfers this kinetic 


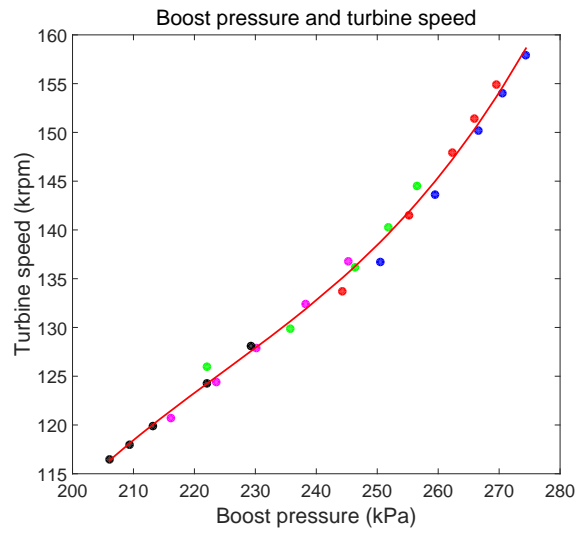

(a) $p_{i n}$ and $\omega$ at no EGR

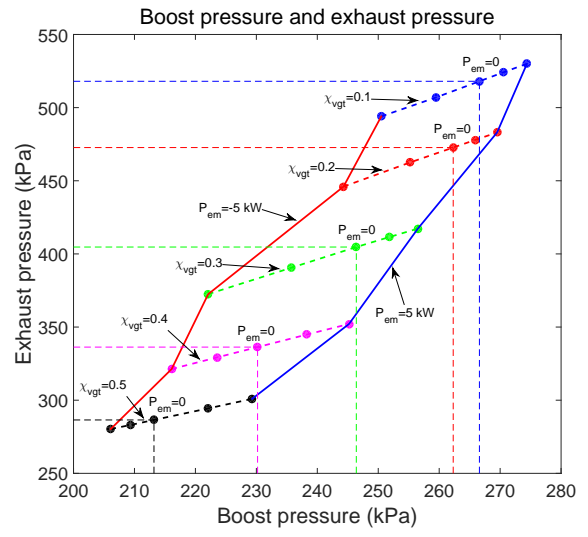

(c) $p_{\text {in }}$ and $p_{\text {exh }}$ at no EGR

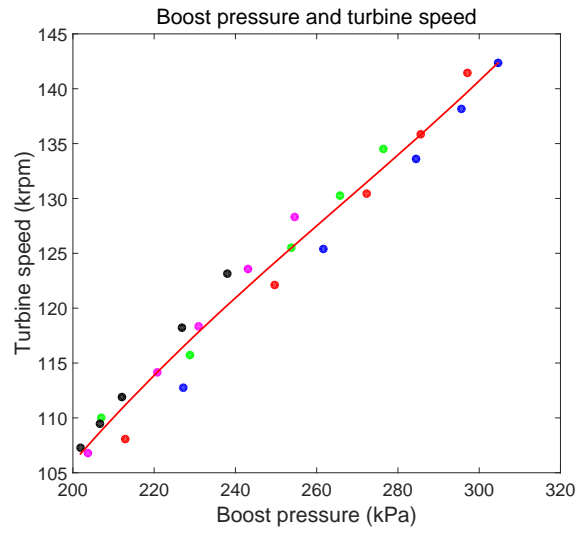

(b) $p_{\text {in }}$ and $\omega$ at $\chi_{\text {egr }}=0.3$

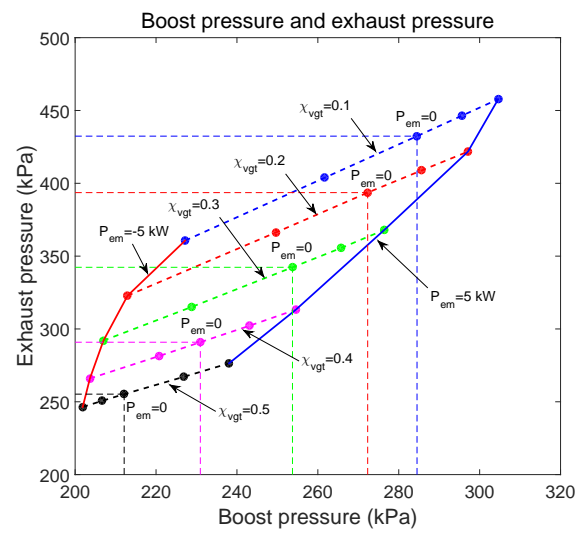

(d) $p_{\text {in }}$ and $p_{\text {exh }}$ at $\chi_{\text {egr }}=0.3$

Figure 4: Relation between boost pressure, turbine speed, and exhaust pressure

energy to the fresh air, which is a fast process. These relations explain why there is an almost linear relation between $p_{i n}$ and $\omega$. As a comparison, Fig. 4(c) and Fig. 4(d) show $p_{\text {exh }}$ varies considerably according to different settings on both $\chi_{v g t}$ and $P_{e m}$, which offers significant flexibility. Based on the analysis on the fuel economy and air system couplings, the control variables are selected as

$$
y=\left[\begin{array}{lll}
p_{i n}, & p_{e x h}, & W_{e g r}
\end{array}\right]^{\mathrm{T}},
$$

with the control inputs of

$$
u=\left[\begin{array}{lll}
\chi_{v g t}, & P_{e m}, & \chi_{e g r}
\end{array}\right]^{\mathrm{T}} .
$$


By properly regulating each element of $y$, engine efficiency can be maximized in the specified layout, together with a fast response in transients.

\section{Low Level Controller Design}

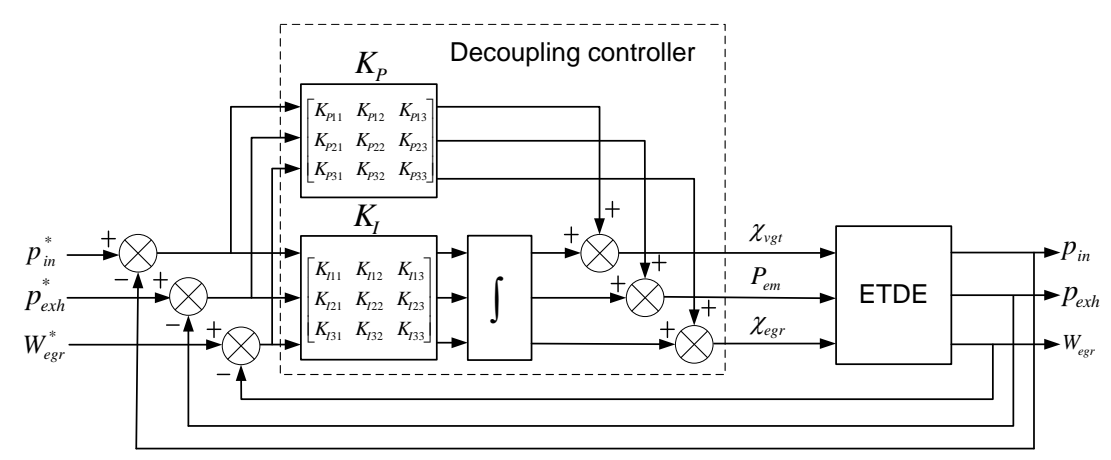

Figure 5: The diagram of ETDE air system control

Distributed proportional-integral (PI) controllers are commonly used in the conventional turbocharged diesel engines in industrial cases. The control variables are normally $p_{i n}$ and $W_{e g r}$ with the control inputs of $\chi_{v g t}$ and $\chi_{e g r}$. However, the new layout of the ETDE changes the dynamics significantly. Therefore the gain values of the PI controllers require to be re-designed in the 3I3O structure. Since it is time consuming to tune the PI gain values individually, designing a centralized MIMO controller would greatly reduce the calibration effort. Moreover, consideration of the internal couplings will improve the tracking performance. The low level $3 \mathrm{I} 3 \mathrm{O}$ control diagram is illustrated in Fig. 5, in the form of a 3I3O PI controller, whose control gains $K_{P i j}$ and $K_{I i j}(i=1,2,3, j=1,2,3)$ are to be tuned by the $H_{\infty}$ method; $p_{i n}^{*}, p_{e x h}^{*}$, and $W_{e g r}^{*}$ are the setpoints of $p_{i n}, p_{e x h}$, and $W_{e g r}$, respectively.

\subsection{Control Problem Formulation}

At a specified operating point, the ETDE air system model can be expressed as:

$$
\left\{\begin{array}{l}
x(k+1)=A x(k)+B u(k) \\
y(k)=C x(k)
\end{array},\right.
$$

where $x \in \mathbb{R}^{n}, u \in \mathbb{R}^{3}$, and $y \in \mathbb{R}^{3}$ are the state vector, input vector, and output vector, respectively; $A, B$, and $C$ are coefficient matrices to be identified from 
the time domain data. Considering external disturbances in modelling, the ETDE model can be augmented as:

$$
\left[\begin{array}{c}
x(k+1) \\
z(k) \\
y(k)
\end{array}\right]=\left[\begin{array}{ccc}
A & B_{1} & B_{2} \\
C_{1} & D_{11} & D_{12} \\
C_{2} & D_{21} & D_{22}
\end{array}\right]\left[\begin{array}{c}
x(k) \\
w(k) \\
u(k)
\end{array}\right],
$$

where $w \in \mathbb{R}^{m_{1}}$ is the vector of exogenous inputs, $z \in \mathbb{R}^{p_{1}}$ is the vector of regulated outputs. In the proposed ETDE control problem, $w$ includes fuel rate, desired speed and load, and other regulating variables, whilst $z$ includes pressures, temperatures, flow rates, and the output signals.

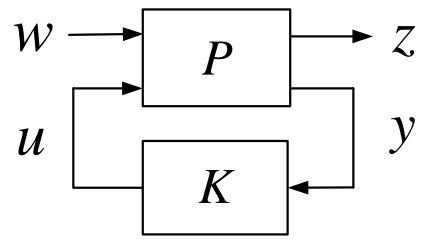

Figure 6: Low level controller block diagram

The full-order controller block diagram and the control implementation structure of the ETDE are illustrated in Fig. 6, while $P$ and $K$ are the controlled plant and the dynamic output feedback control gain matrix to be designed.

A $H_{\infty}$ controller $u=K y$ addressing the following optimisation problem is to be built:

$$
\begin{aligned}
& \underset{g}{\operatorname{minimize}}: \max _{i}\left\{\left\|T_{w_{i} \rightarrow z_{i}}(P, K)\right\|\right\} \\
& \text { subject to : } \max _{j}\left\{\left\|T_{w_{j} \rightarrow z_{j}}(P, K)\right\|\right\} \leq 1,
\end{aligned}
$$

where $g$ denotes the vector of manipulated parameters, $\left\|T_{w \rightarrow z}\right\|$ denotes the closed loop relationship from $w$ to $z$, and $\|\cdot\|$ is either the $H_{\infty}$ norm or the $H_{2}$ norm, $i$ and $j$ are the index of soft (nice to have) objectives and hard (must have) constraints, respectively. The optimisation problem (11) means minimization of the worstcase value of the soft objectives while satisfying all the hard constraints. All the terms are normalized in the formulation.

\subsection{Model Identification}

The general procedure of model identification is shown in Fig. 7. Applying the perturbation signals of $u(t)$ on the physical ETDE model, the generated $y(t)$ 


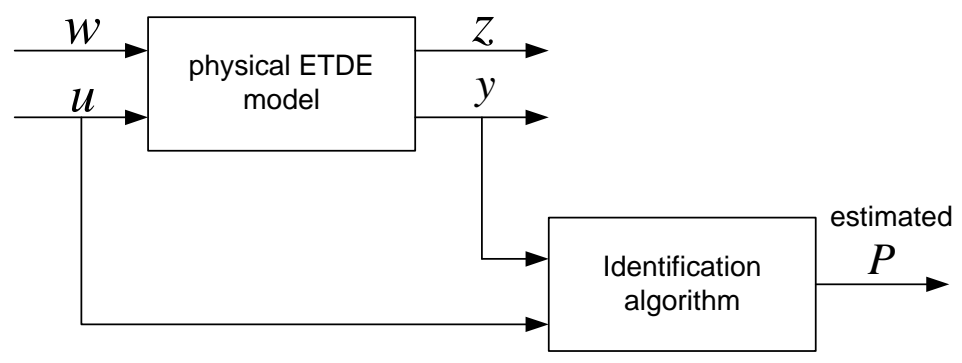

Figure 7: Model identification diagram
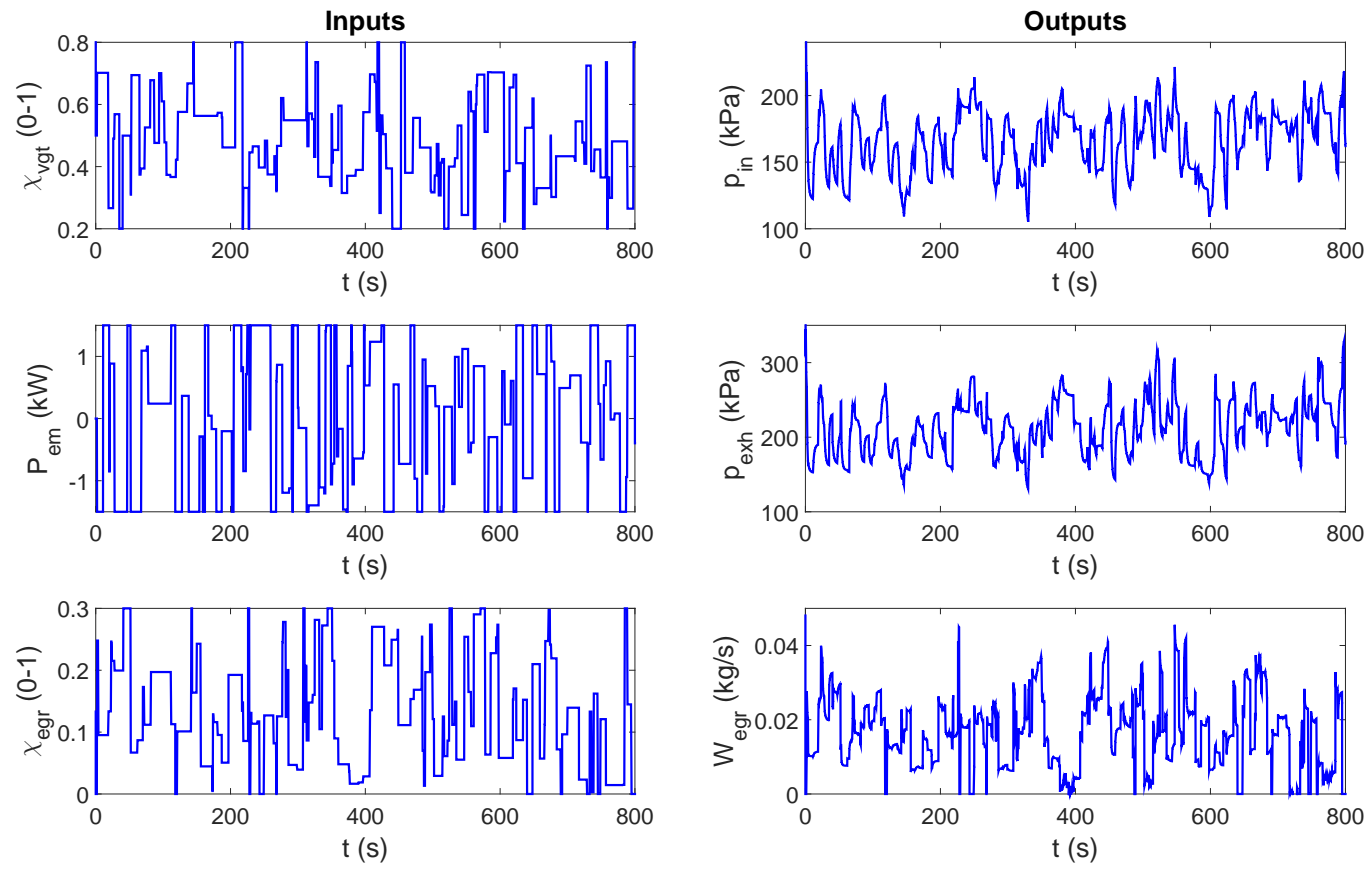

Figure 8: Calibration for model identification

is measured and recorded. The calibration data $u(t)$ and $y(t)$ are categorized into training data and validation data. A group of candidate state space models with different orders would be identified from the training data. Afterwards, $u(t)$ in the validation data is applied on the candidate models to produce predicted outputs. By comparing the real outputs and predicted outputs, the model with the best fitting results will be selected as the proper model.

As an example, the calibration data on the Dynasty model at the operating point of $1800 \mathrm{rpm}$ and $260 \mathrm{Nm}$ is illustrated in Fig. 8. The calibration has contin- 

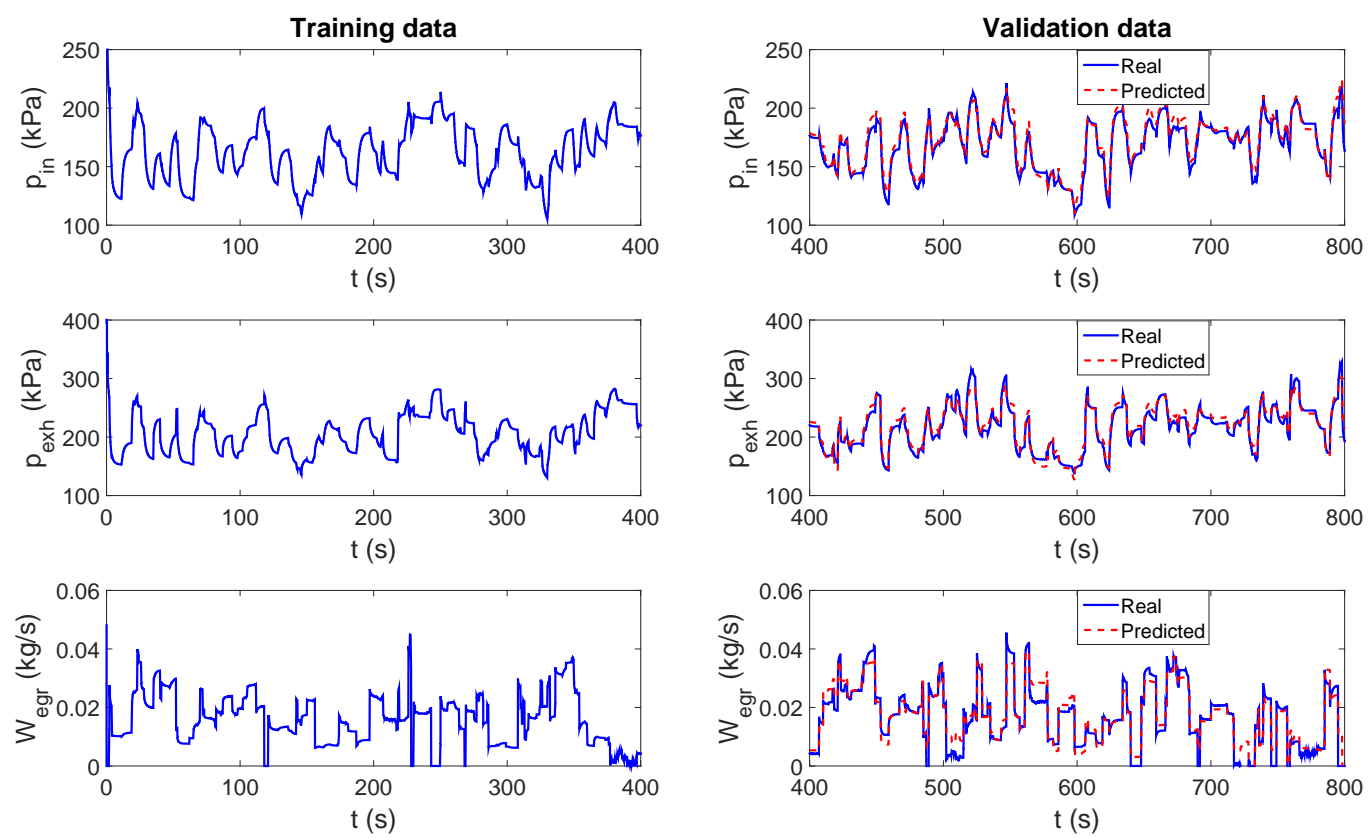

Figure 9: Training and validation in model identification

ued for 800 seconds, while the action ranges of $\chi_{v g t}, P_{e m}$, and $\chi_{e g r}$ are limited as $[0.2,0.8],[-1.5 \mathrm{~kW}, 1.5 \mathrm{~kW}]$, and $[0,0.3]$, respectively. The generated first half 400 seconds data are used for training and the latter half 400 seconds data are used for validation.

The normalized root-mean-square deviation (NRMSD) value is introduced to quantify the difference between the predicted values and measured values, which is expressed as a percentage. For the $i^{\text {th }}$ variable in $y$, the NRMSD value is defined as

$$
F(i)=1-\frac{\sqrt{\sum_{j=1}^{m}\left(y_{v}(i, j)-y_{p}(i, j)\right)^{2}}}{\sqrt{\sum_{j=1}^{m}\left(y_{v}(i, j)-\bar{y}_{v}(i)\right)^{2}}}, \quad i=1,2,3,
$$

where $y_{v}$ is the validation data, $y_{p}$ is the predicted data, $\bar{y}_{v}(i)$ is the mean value of $y_{v}(i)$ :

$$
\bar{y}_{v}(i)=\sum_{j=1}^{m} y_{v}(i, j) / m, \quad i=1,2,3,
$$


Table 3: Performance indices in low level controller design

\begin{tabular}{|c|c|c|c|}
\hline \multicolumn{2}{|c|}{ Performance indices } & Operating point \\
\cline { 2 - 4 } & Settling time (s) & A & B \\
\hline \multirow{2}{*}{ Soft objectives } & Steady state error (\%) & 0.5 & 0.1 \\
\cline { 2 - 4 } & Gain margin (dB) & 7 & 0.1 \\
\hline \multirow{2}{*}{ Hard constraints } & Phase margin (degree) & 45 & 45 \\
\cline { 2 - 4 } &
\end{tabular}

and $m$ is the number of validation data samples.

By comparing the $F(i)$, a third-order model with the highest value is selected as the proper model at the specified operating point. The model validation results are illustrated in Fig. 9, while the NRMSD values on $p_{i n}, p_{e x h}$, and $W_{\text {egr }}$ are 85\%, $83 \%$, and $75 \%$, respectively. The identified coefficient matrices are as follows:

$$
\begin{aligned}
A & =\left[\begin{array}{ccc}
0.7894 & -0.8801 & 0.2418 \\
0.0507 & 0.7156 & 0.0578 \\
0.1415 & -1.1459 & 1.2426
\end{array}\right], \\
B & =\left[\begin{array}{ccc}
-0.2660 & -0.0000 & 0.3055 \\
0.7990 & 0.0028 & -0.1764 \\
2.7721 & 0.0104 & -0.5716
\end{array}\right], \\
C & =\left[\begin{array}{ccc}
-12.1863 & -576.9938 & 165.1306 \\
-99.0510 & -1084.0446 & 298.8131 \\
0.0732 & 0.3462 & -0.0931
\end{array}\right] .
\end{aligned}
$$

\subsection{Controller Synthesis}

A nonsmooth $H_{\infty}$ synthesis method is employed to tune the controller gain values since it excels in handling internal couplings [38]. A mixed set of frequencyand time- domain indices can be addressed by the nonsmooth $H_{\infty}$ synthesis method.

In the trenching test cycle which is typical for heavy-duty engines, the engine speed is fixed at $1800 \mathrm{rpm}$, while the load changes mainly between $200 \mathrm{Nm}$ and $800 \mathrm{Nm}$. Therefore, two operating points, (1800 rpm, $260 \mathrm{Nm})$, and (1800 rpm, $700 \mathrm{Nm}$ ), are chosen as the operating points for testing to reveal the frequent usage in practice. In generating the decoupling control law, the performance indices are to be specified. The soft objectives are chosen as the steady state error and the settling time. The hard constraints are chosen as the stability margins including the phase margin and the gain margin. The performance indices at the two specified operating points are shown in Table 3, where A and B denote the low load 


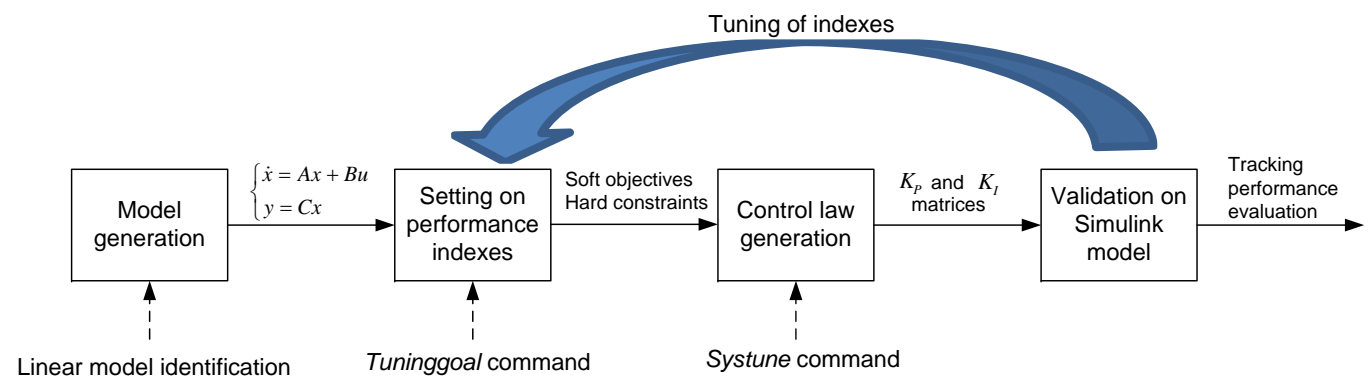

Figure 10: Workflow in developing low level controller

point and the high load point, respectively. From the engineering point of view, the workflow in designing the low level controller is illustrated as Fig. 10, where the systune solver in Matlab is used to generate the control law, and the performance indices are set by the Tuninggoal command [39]. The control gain matrices of the low level controller are computed as

$K_{P}=\left[\begin{array}{ccc}-0.0047 & -0.0003 & -0.1643 \\ 0.0055 & -0.0002 & 0.1691 \\ 0.0043 & -0.0001 & 1.7834\end{array}\right], K_{I}=\left[\begin{array}{ccc}0.0010 & -0.0298 & -0.0522 \\ 0.1250 & -0.0002 & -8.3433 \\ -0.0001 & -0.0158 & 13.0723\end{array}\right]$.

at (1800 rpm, 260Nm), and

$K_{P}=\left[\begin{array}{ccc}-0.0104 & 0.0007 & -0.8525 \\ 0.0087 & -0.0013 & 1.3314 \\ -0.0009 & -0.0002 & 0.3255\end{array}\right], K_{I}=\left[\begin{array}{ccc}-0.0248 & -0.0084 & -4.5212 \\ 0.2297 & -0.0764 & -1.0750 \\ 0.0056 & -0.0005 & 22.5241\end{array}\right]$

at (1800 rpm, 700Nm).

At point $\mathrm{A}, p_{i n}^{*}$ and $W_{e g r}^{*}$ are fixed as $170 \mathrm{kPa}$ and $0.03 \mathrm{~kg} / \mathrm{s}$, respectively, while $p_{\text {exh }}^{*}$ changes as a series of step-changed values between $180 \mathrm{kPa}$ and 260 $\mathrm{kPa}$. The incremental pace on $p_{\text {exh }}^{*}$ is set as $10 \mathrm{kPa}$ every 15 seconds. The results in Fig. 11 show that the tracking of all three variables are very desirable. $\chi_{v g t}$ and $\chi_{\text {egr }}$ both move toward to close when $p_{\text {exh }}^{*}$ increases. At the meantime, the ETA is generating more power to stabilize $p_{i n}$ and $W_{\text {egr }}$. To observe the dynamics more clearly, the magnified tracking performance and actuator actions in a shorten period with just one step change on $p_{\text {exh }}^{*}$ is shown in Fig. 12. All the control variables are attracted to the desired trajectories fast despite the step change on $p_{\text {exh }}^{*}$, and only minor overshooting is introduced.

Similarly, the simulation results at point B are shown as Fig. 13. $p_{i n}^{*}$ and $W_{e g r}^{*}$ are set as $240 \mathrm{kPa}$ and $0.05 \mathrm{~kg} / \mathrm{s}$, respectively, while $p_{\text {exh }}^{*}$ changes as a series of 

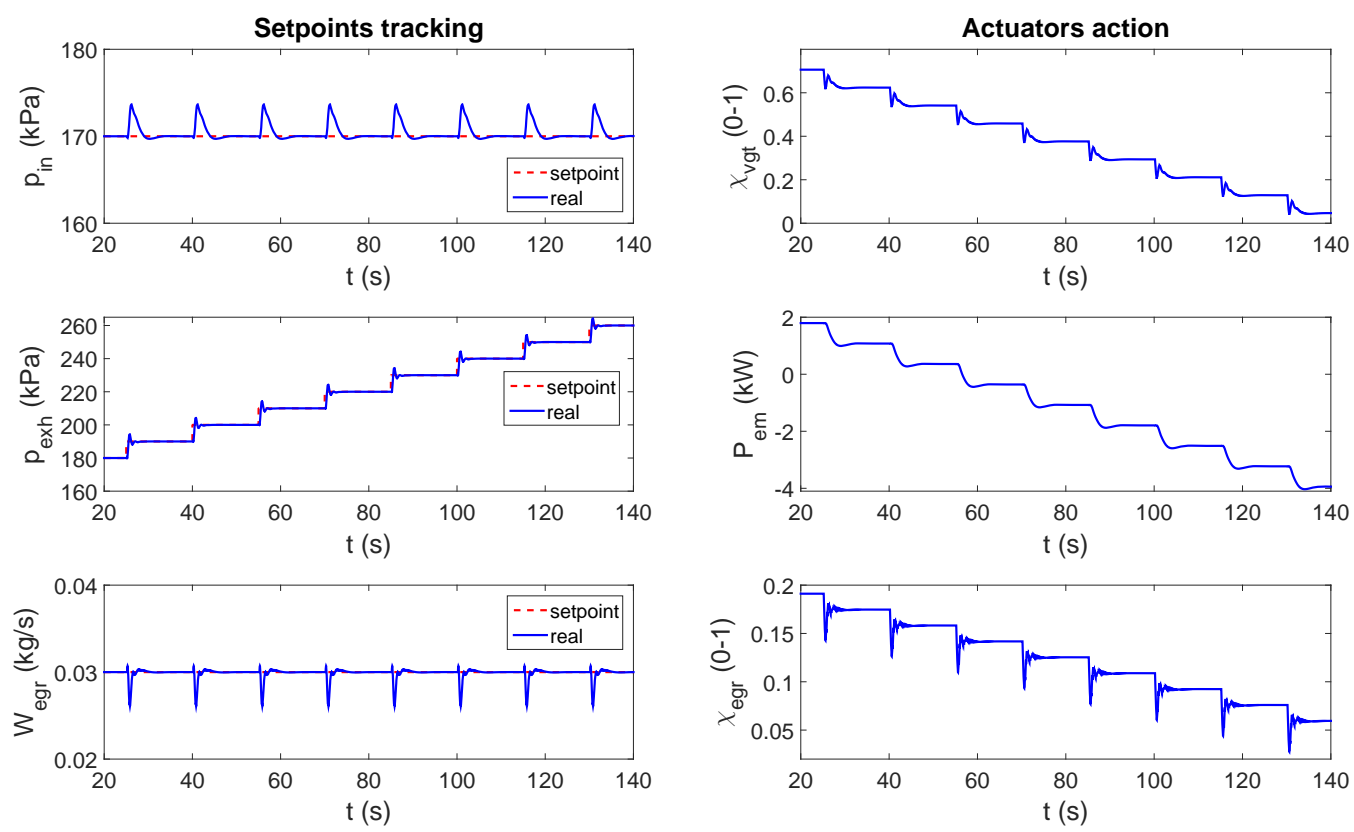

Figure 11: Mathematical simulation results at $1800 \mathrm{rpm}, 260 \mathrm{Nm}$
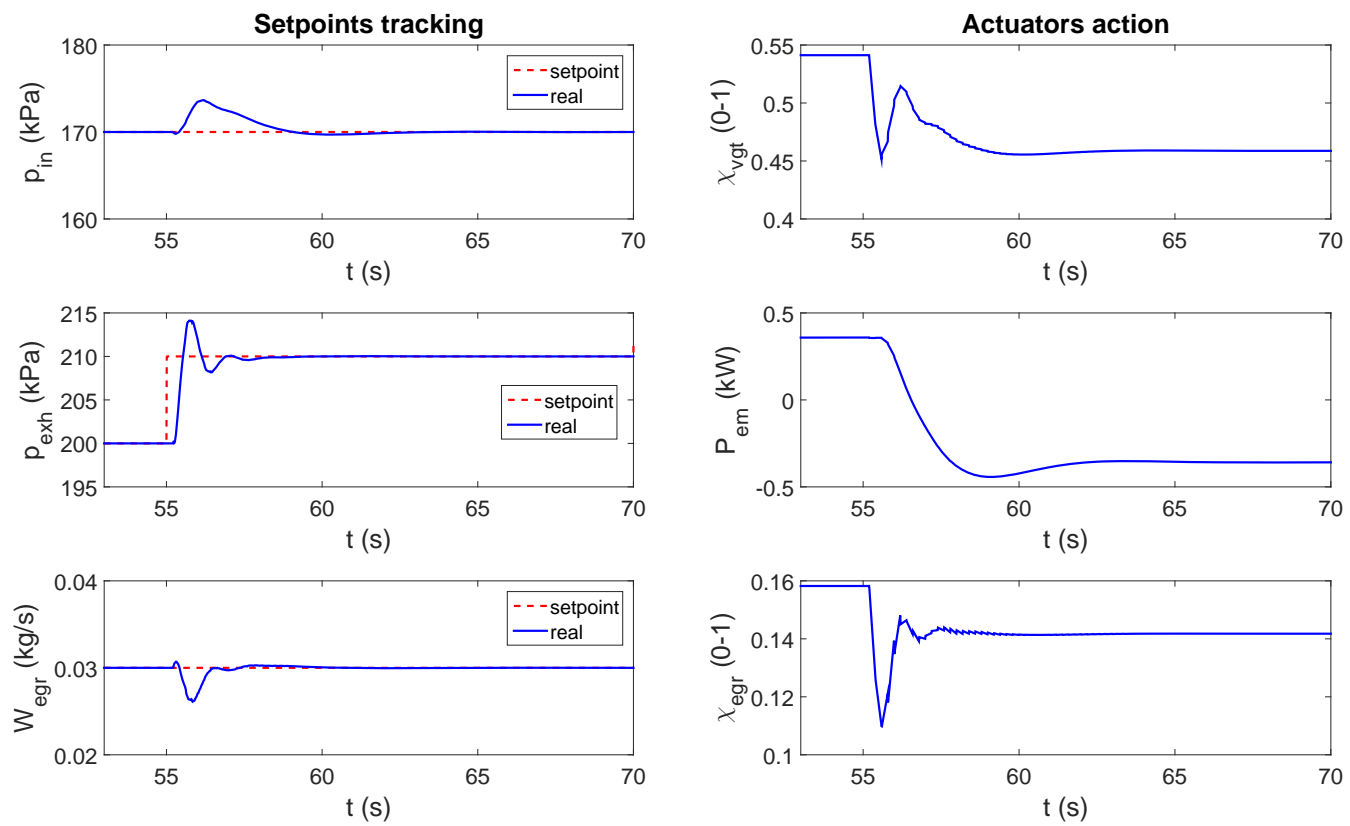

Figure 12: Control behaviour of using the low level controller at $1800 \mathrm{rpm}, 260$ Nm with step change on $p_{e x h}^{*}$ in Simulink 

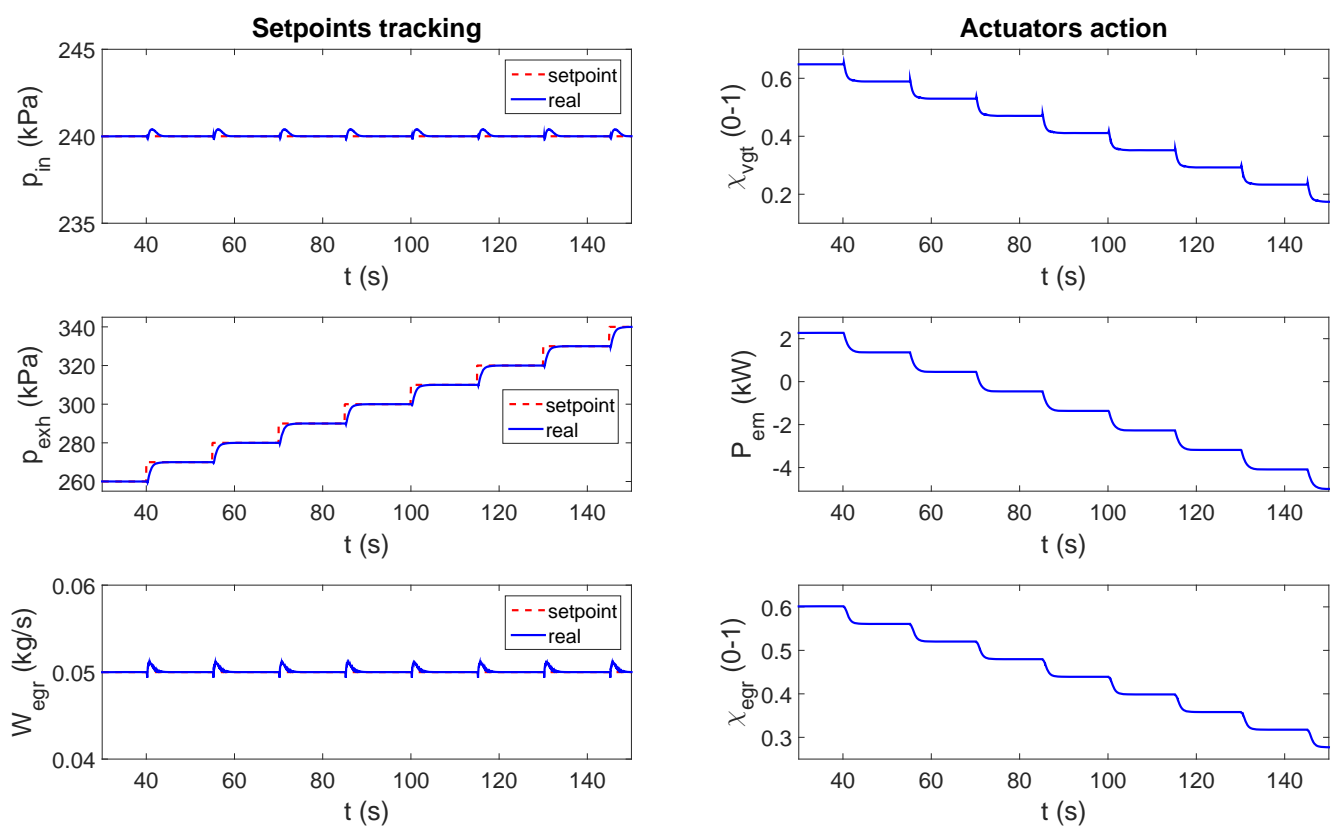

Figure 13: Mathematical simulation results at $1800 \mathrm{rpm}, 700 \mathrm{Nm}$
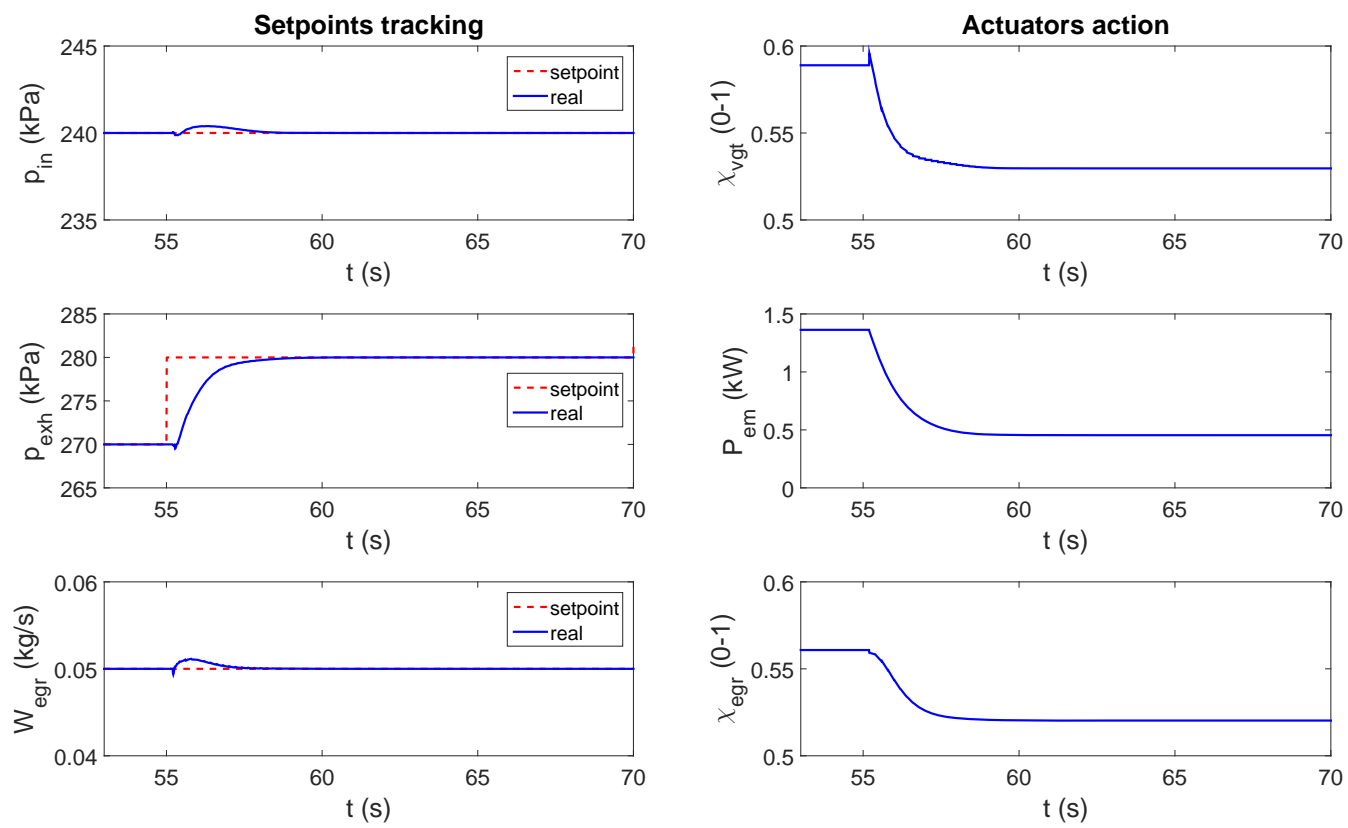

Figure 14: Control behaviour of using the low level controller at $1800 \mathrm{rpm}, 700$ Nm with step change on $p_{e x h}^{*}$ in Simulink 

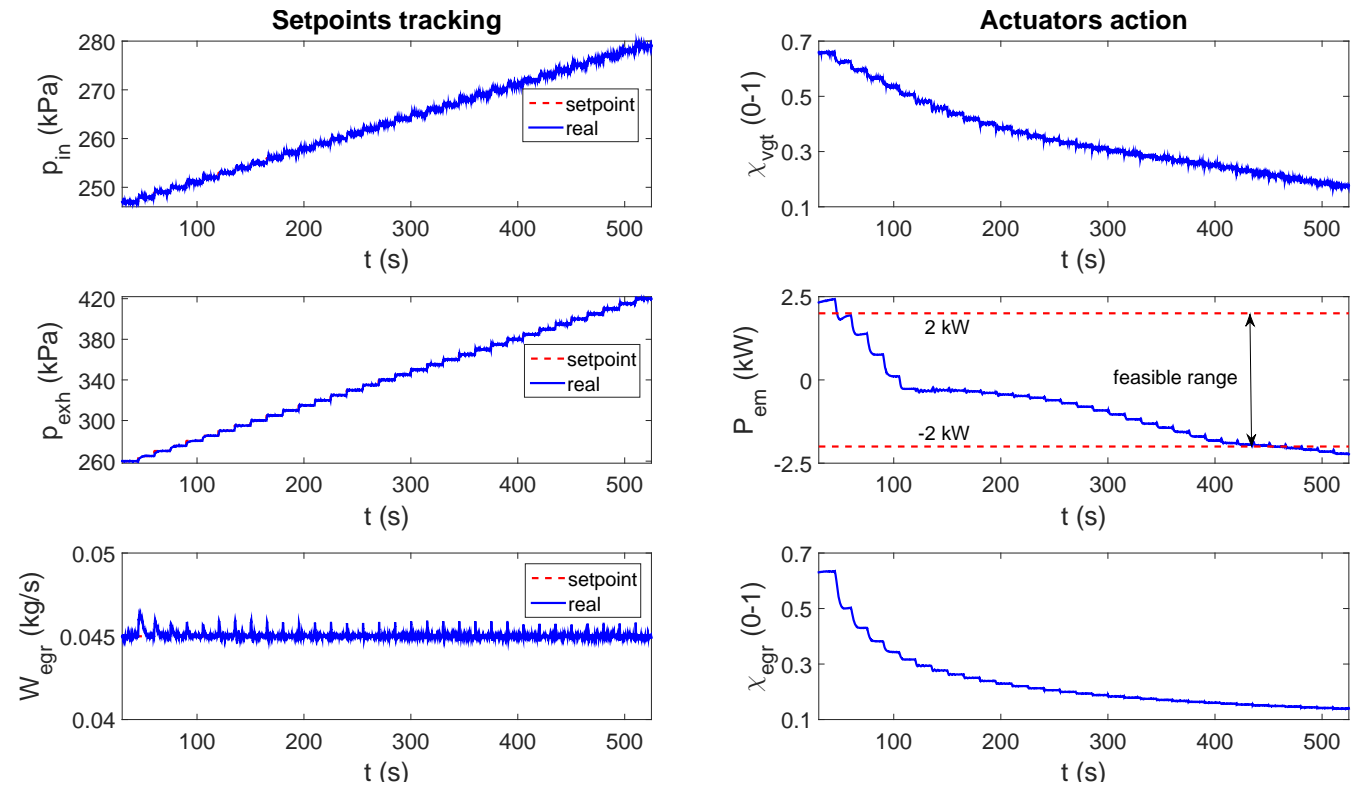

Figure 15: Calibration for the boundaries of $p_{e x h}^{*}$ at $1800 \mathrm{rpm}, 700 \mathrm{Nm}$
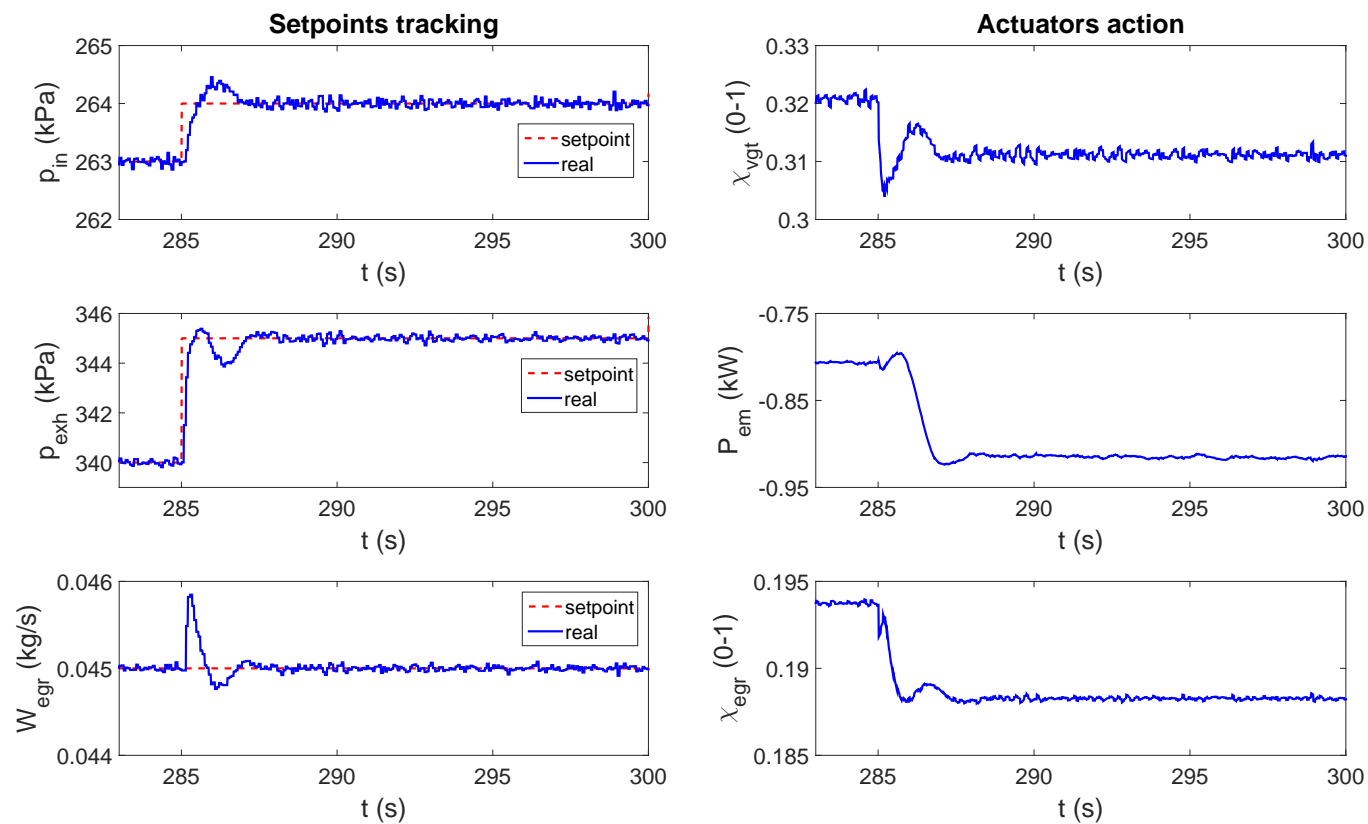

Figure 16: Control behaviour of using the low level controller at $1800 \mathrm{rpm}, 700$ $\mathrm{Nm}$ with step changes on $p_{i n}^{*}$ and $p_{e x h}^{*}$ in

Dynasty 
Table 4: Lookup table of $P_{a}$ and $P_{e m}$ with respect to $p_{e x h}^{*}$

\begin{tabular}{lll}
\hline$p_{e x h}^{*}(\mathrm{kPa})$ & $P_{a}(\mathrm{~kW})$ & $P_{e m}(\mathrm{~kW})$ \\
\hline 265 & 351.26 & 1.94 \\
275 & 353.25 & 0.76 \\
285 & 355.17 & -0.27 \\
295 & 356.95 & -0.31 \\
305 & 358.65 & -0.34 \\
315 & 360.36 & -0.44 \\
325 & 362 & -0.54 \\
335 & 363.63 & -0.7 \\
345 & 365.27 & -0.92 \\
355 & 366.9 & -1.18 \\
365 & 368.54 & -1.44 \\
375 & 370.11 & -1.7 \\
385 & 371.74 & -1.89 \\
395 & 373.38 & -1.97 \\
\hline
\end{tabular}

step-changed values between $260 \mathrm{kPa}$ and $340 \mathrm{kPa}$. The incremental pace on $p_{e x h}^{*}$ is also set as $10 \mathrm{kPa}$ every 15 seconds. The zoomed in results are illustrated in Fig. 14 for better observation. The tracking performance is still very fast and accurate.

\section{Supervisory Level Controller Design}

The supervisory level controller is designed to find the optimal value of $y^{*}$ in real-time for energy management. Prior to the online implementation, an offline calibration on the boundaries of $y^{*}$ is required to guarantee $y^{*}$ are reachable.

\subsection{Generation of Setpoints}

In industrial cases, the values of $p_{i n}^{*}$ and $W_{e g r}^{*}$ are obtained from the engine calibration settings within the ECU. Therefore, only $p_{e x h}^{*}$ is to be determined. A calibration-based approach is implemented to get the boundary values of $p_{e x h}^{*}$. In the calibration, $p_{e x h}^{*}$ is set as an incrementally increasing series. The developed low level controller is applied on the Dynasty ETDE model to track $p_{e x h}^{*}$. The value of $p_{e x h}^{*}$ is feasible only if it can be tracked well in the allowed ranges of actuator actions. If the actuator actions violate the allowed ranges in some cases, it implies the $p_{e x h}^{*}$ value is beyond its boundary. 
Fig. 15 shows the calibration of the boundary of $p_{e x h}^{*}$ at $1800 \mathrm{rpm}, 700 \mathrm{Nm}$, while $p_{\text {exh }}^{*}$ increases from $260 \mathrm{kPa}$ to $420 \mathrm{kPa}$ stepwise, with the incremental pace of $5 \mathrm{kPa}$ every 15 seconds. The $p_{i n}^{*}$ is set as the mean value of the ECU-generated setpoints at each $p_{\text {exh }}^{*}$ step. Since $W_{e g r}^{*}$ changes very slowly, it is fixed as 0.045 $\mathrm{kg} / \mathrm{s}$. It can be observed that all the given $p_{\text {exh }}^{*}$ values are tracked well. In this case, the action ranges of $\chi_{v g t}, P_{e m}$, and $\chi_{e g r}$ are limited as [0.1, 0.9], [-2 kW, 2 $\mathrm{kW}]$, and $[0,1]$, which are indicated in the right column of Fig. 15. As observed, the feasible $p_{e x h}^{*}$ is located in the band of [265 kPa, $395 \mathrm{kPa}$ ]. Similarly, the boundaries of $p_{e x h}^{*}$ at other operating points are also determined in the same way. At the other untested operating points, the boundaries are obtained by means of gain scheduling. Selected fuel power and EM power in Fig. 15 are listed in Table 4. When the EM running in the generating mode, its power changes more gently compared with the motoring mode, as shown in Table 4. This is because when the EM is running in the motoring mode and the generating mode, the power is obtained from

$$
P_{\mathrm{em}}=T_{\mathrm{em}} \omega_{\mathrm{em}} / \eta\left(T_{\mathrm{em}}, \omega_{\mathrm{em}}\right)
$$

and

$$
P_{\mathrm{em}}=\eta\left(T_{\mathrm{em}}, \omega_{\mathrm{em}}\right) T_{\mathrm{em}} \omega_{\mathrm{em}},
$$

respectively, where $T_{\mathrm{em}}$ and $\omega_{\mathrm{em}}$ are the EM torque and speed, respectively; $\eta\left(T_{\mathrm{em}}, \omega_{\mathrm{em}}\right)$ is the EM efficiency regarding to $T_{\mathrm{em}}$ and $\omega_{\mathrm{em}}$. Therefore, less power can be generated under the same condition because of power losses.

\subsection{Optimisation of Setpoints}

The supervisory level controller realizes the optimisation problem in real-time by minimizing an instantaneous cost function. The energy equivalent factor in (2) is designed as

$$
s=K_{P} \Delta \mathrm{SOC},
$$

where $K_{P}$ is a positive constant, and

$$
\triangle \mathrm{SOC}=\mathrm{SOC}-\mathrm{SOC}^{*}
$$

while $\mathrm{SOC}^{*}$ is the desired value of battery SOC.

Without considering electrical energy losses, it is assumed that $P_{e m}$ is equal to $P_{b}$. At different battery SOC values, $P_{a}$ and $P_{b}$ have different weights in the cost function $P_{e q}$. The optimal $p_{e x h}^{*}$ is obtained from the lookup table that corresponds to the minimal $P_{e q}$ as in Table 4 . 


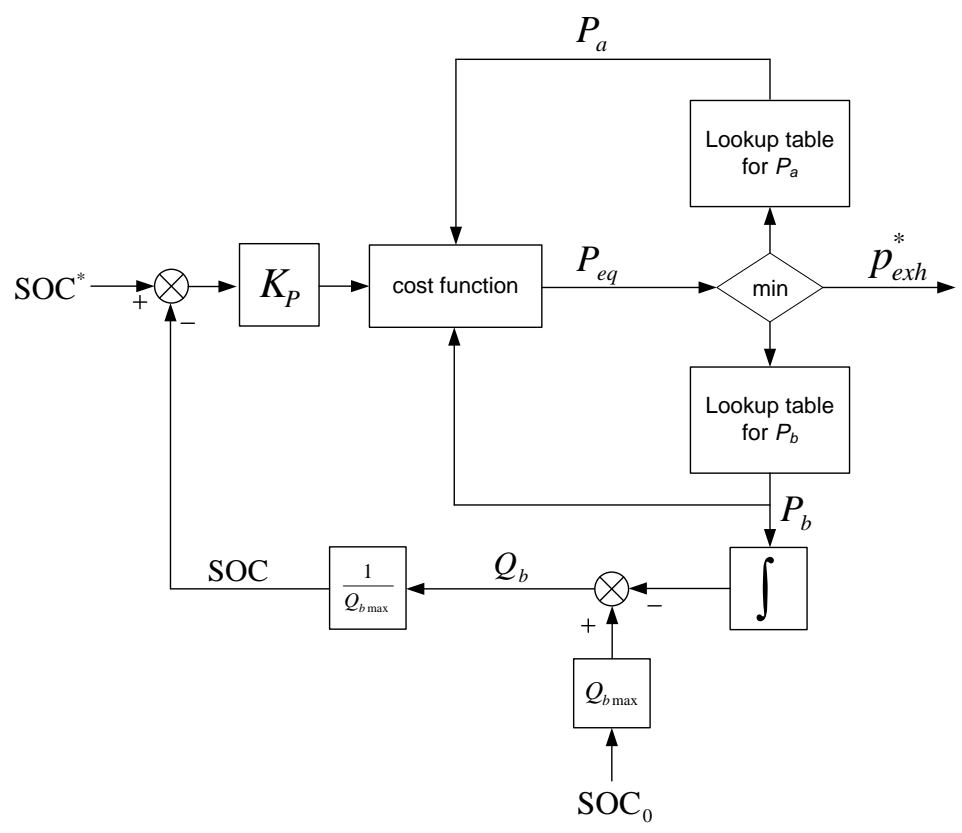

Figure 17: The diagram of supervisory level controller

The diagram of the supervisory level controller is illustrated in Fig. 17, where $Q_{b}$ and $Q_{b \max }$ denote the battery stored energy and battery capacity, respectively. At the supervisory level controller, $p_{\text {exh }}^{*}$ is generated according to the minimized $P_{e q}$, whose value is computed by the feedback variables $P_{a}$ and $P_{b}$, and $s$. The generated $p_{e x h}^{*}$, together with $p_{i n}^{*}$ and $W_{e g r}^{*}$ from the ECU are the setpoints to be tracked. They are sent to the cascaded low level controller.

\section{Physical Simulation Results}

The controllers are built in Matlab/Simulink. For the synchronisation of actions, the sampling frequency of the engine model in Dynasty and the controller in Simulink are both set as $100 \mathrm{~Hz}$. The operating points are also selected as (1800 rpm, $260 \mathrm{Nm}$ ), and (1800 rpm, 700Nm), identical to those in controller synthesis. A block load condition on the switching between the two operating points is also given, while the gain values are scheduled. The values of $p_{i n}^{*}$ and $W_{\text {egr }}^{*}$ are generated in real-time from the embedded setpoint maps in the ECU. 

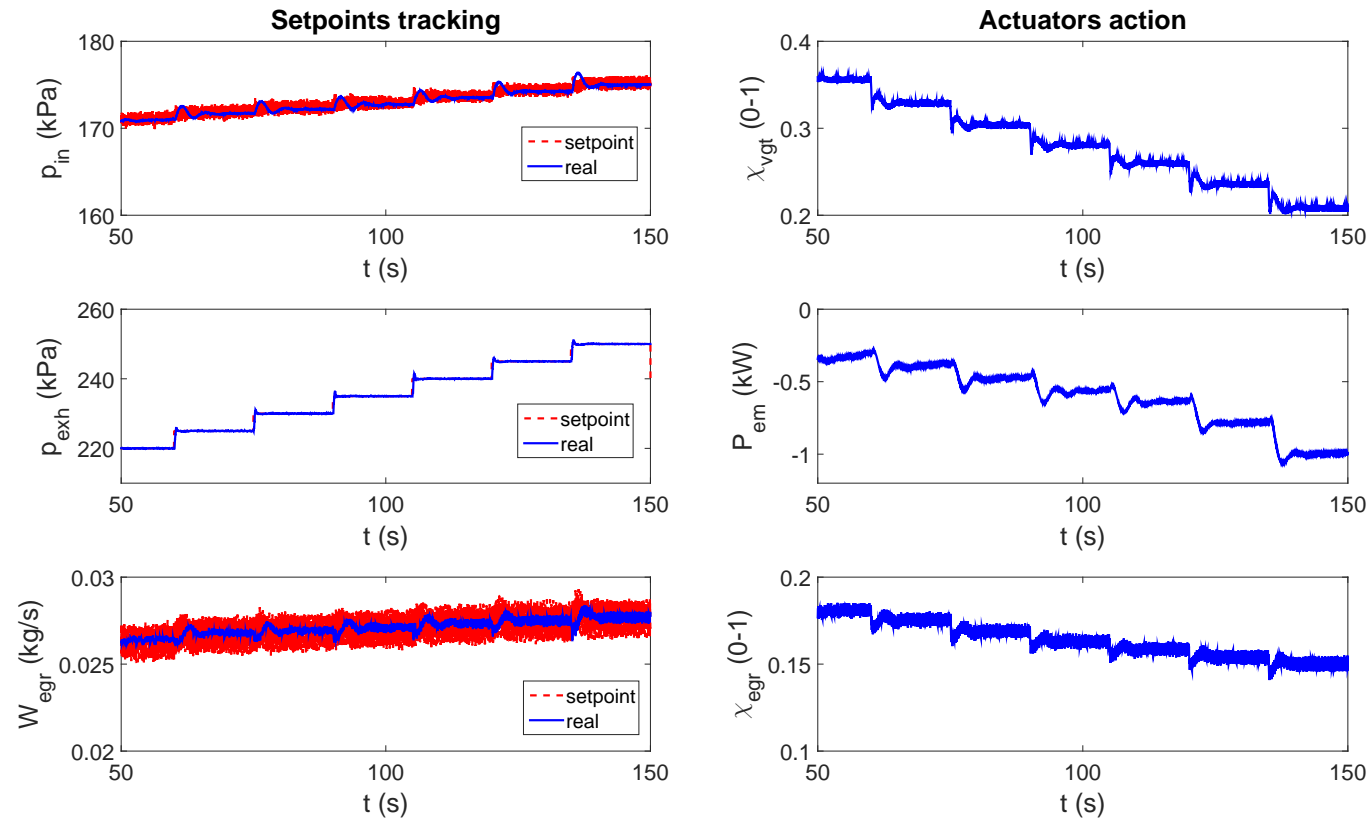

Figure 18: Physical simulation results at $1800 \mathrm{rpm}, 260 \mathrm{Nm}$
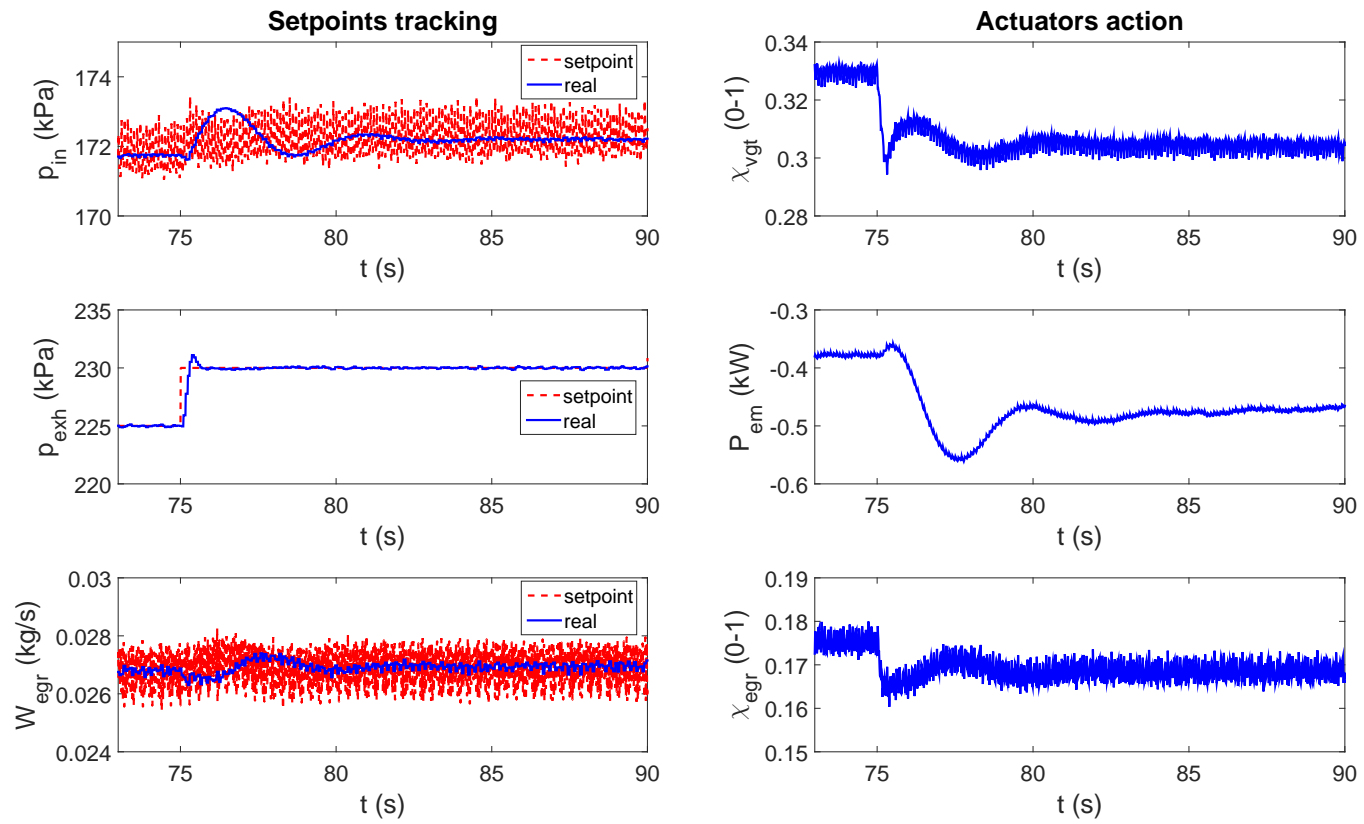

Figure 19: Control behaviour of using the low level controller at $1800 \mathrm{rpm}, 260$ $\mathrm{Nm}$ with step change on $p_{\text {exh }}^{*}$ in 

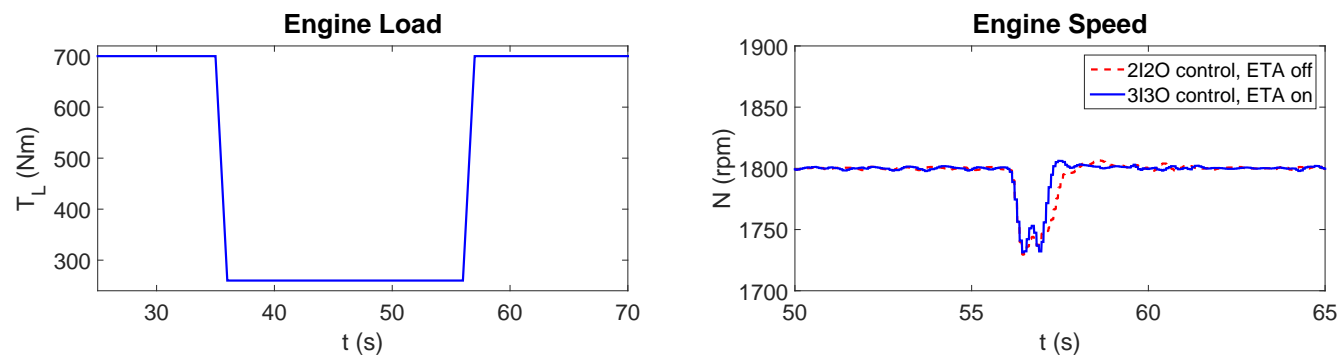

Figure 20: Operating condition at block loads in low level controller test
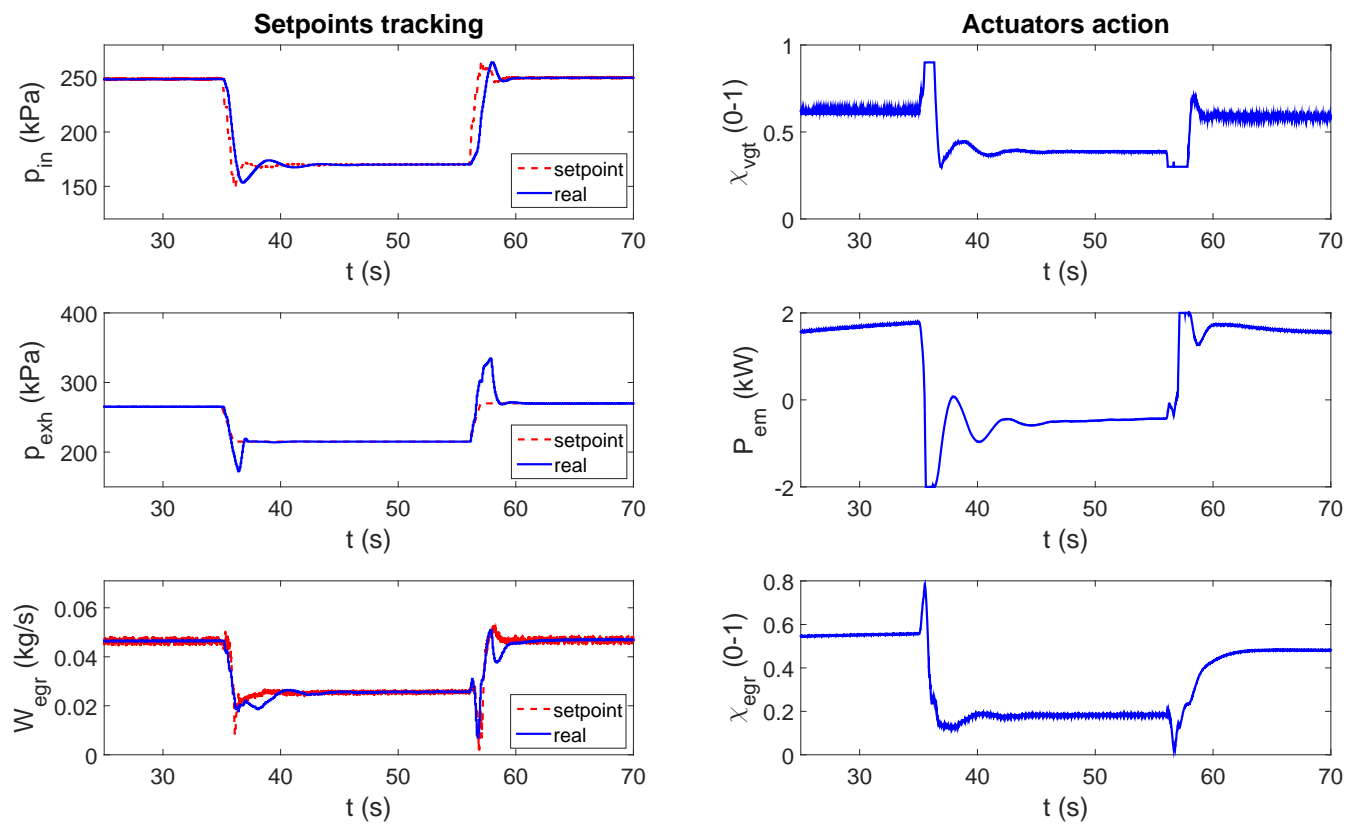

Figure 21: Control behaviour at block loads using low level controller

\subsection{Evaluation of the Low Level Controller}

The tracking performance of using the low level controller at steady states and transients are both evaluated.

\subsubsection{Tracking Evaluation at Steady States}

The simulation results at $(1800 \mathrm{rpm}, 260 \mathrm{Nm})$ are illustrated in Fig. 18. The $p_{e x h}^{*}$ changes as a series of step-changed values between $220 \mathrm{kPa}$ and $250 \mathrm{kPa}$. The incremental pace on $p_{e x h}^{*}$ is set as $5 \mathrm{kPa}$ every 15 seconds. Since $P_{e m}$ is reduced to 

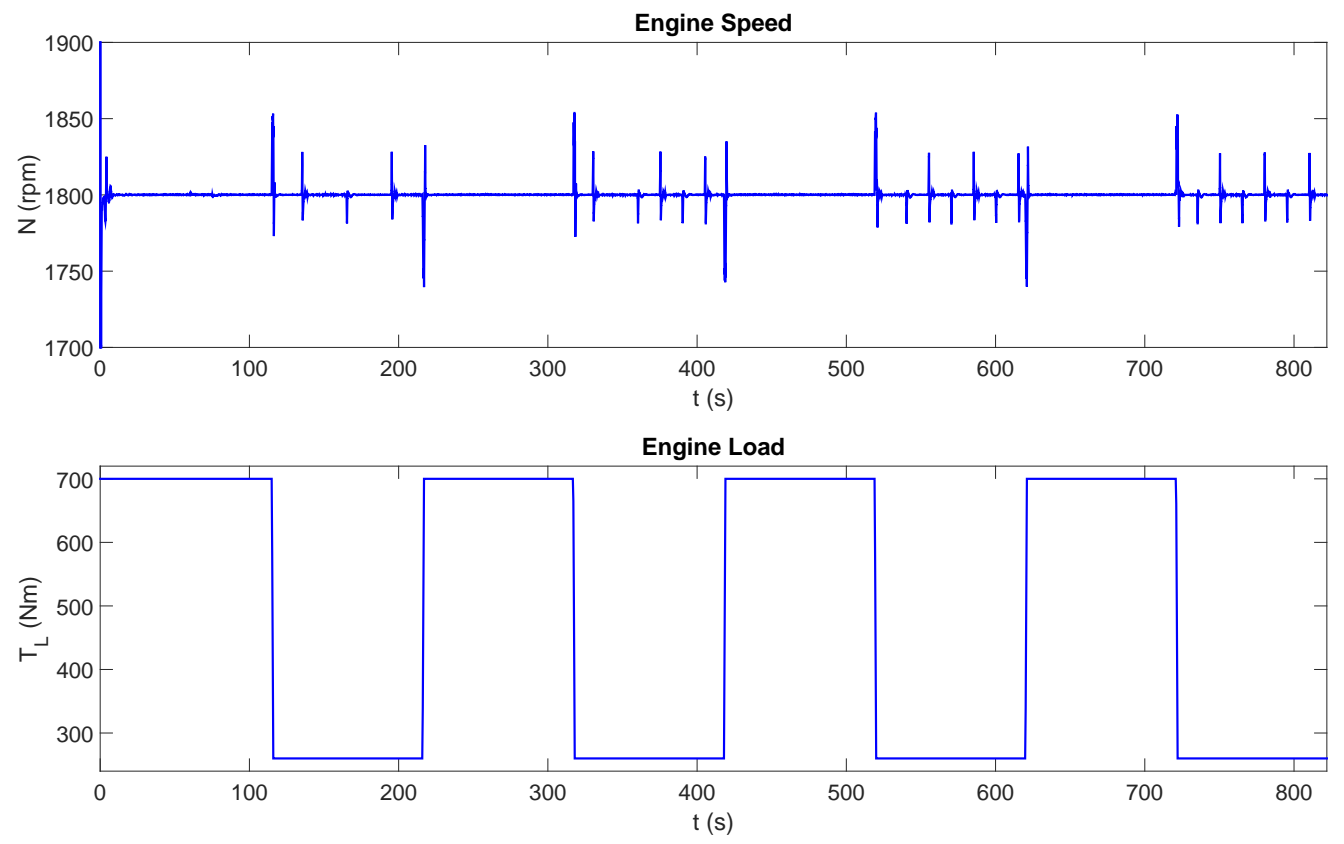

Figure 22: Operating condition in two-level energy management strategy test

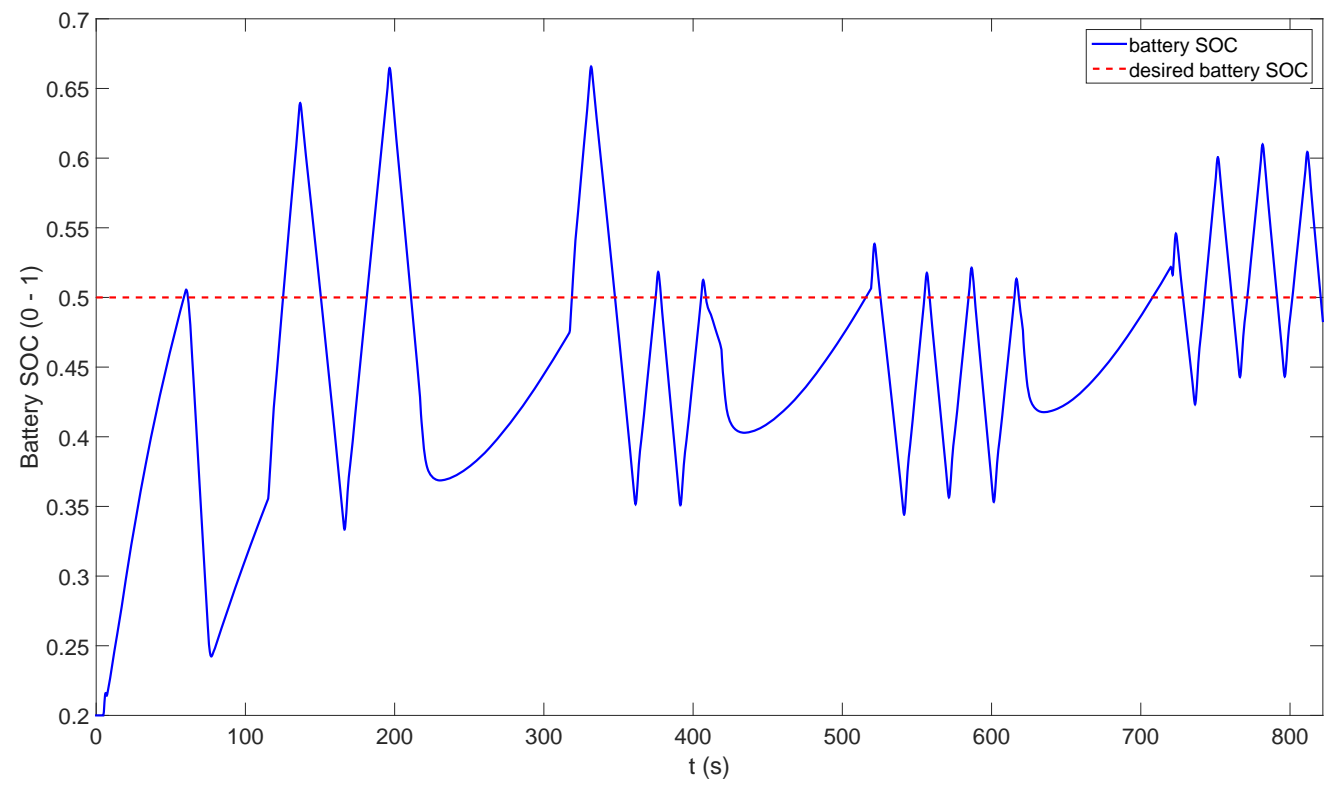

Figure 23: Battery SOC variance with SOC initial value of $20 \%$ 

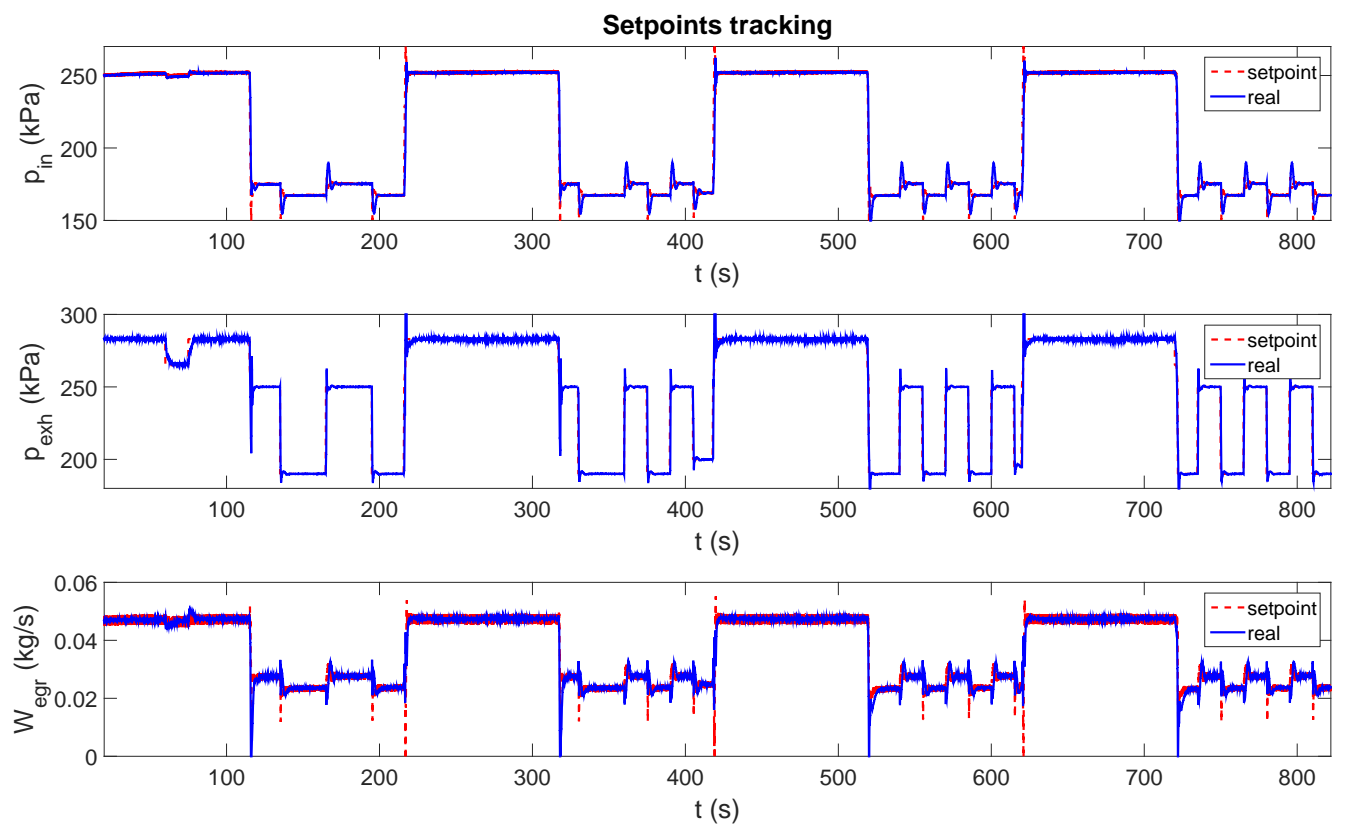

Figure 24: Tracking performance in two-level energy management test
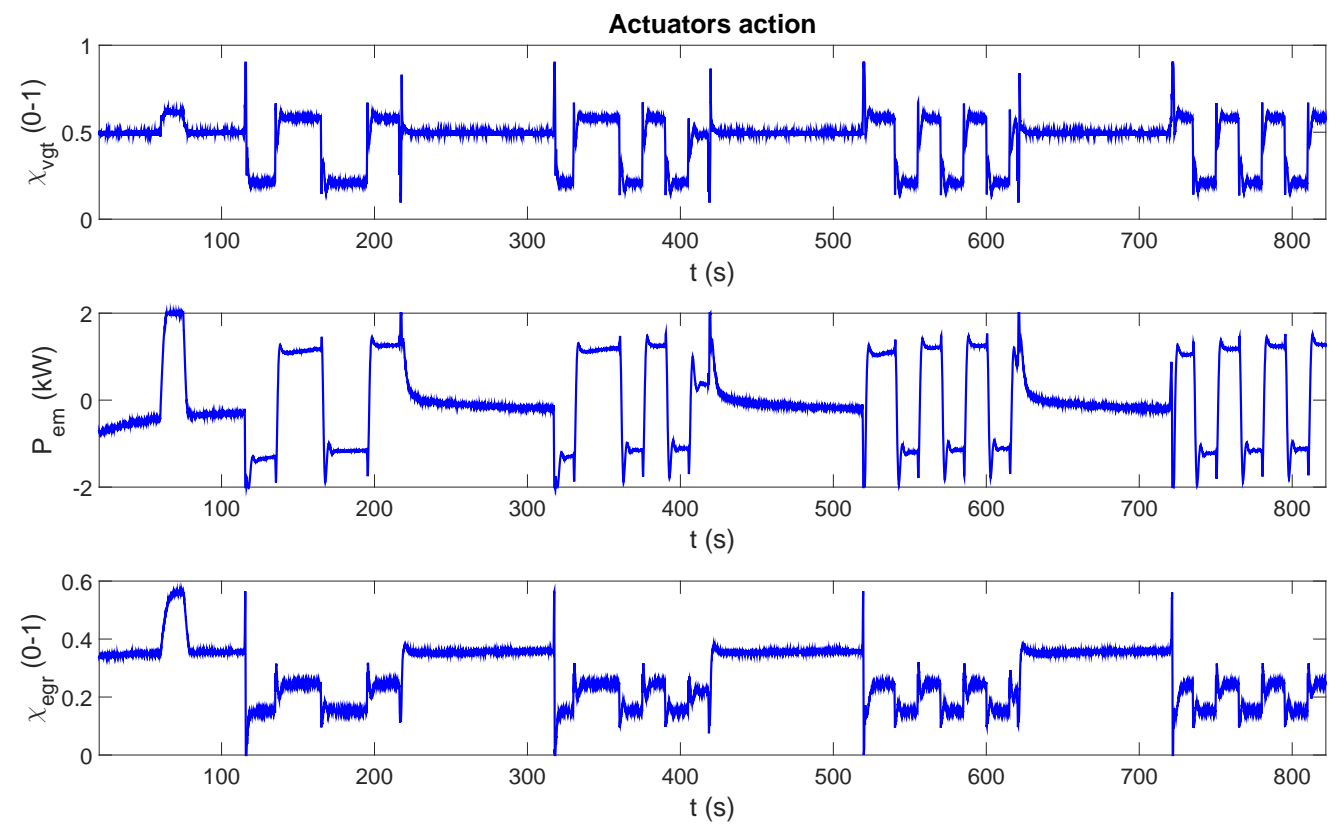

Figure 25: Actuator actions in two-level energy management test 


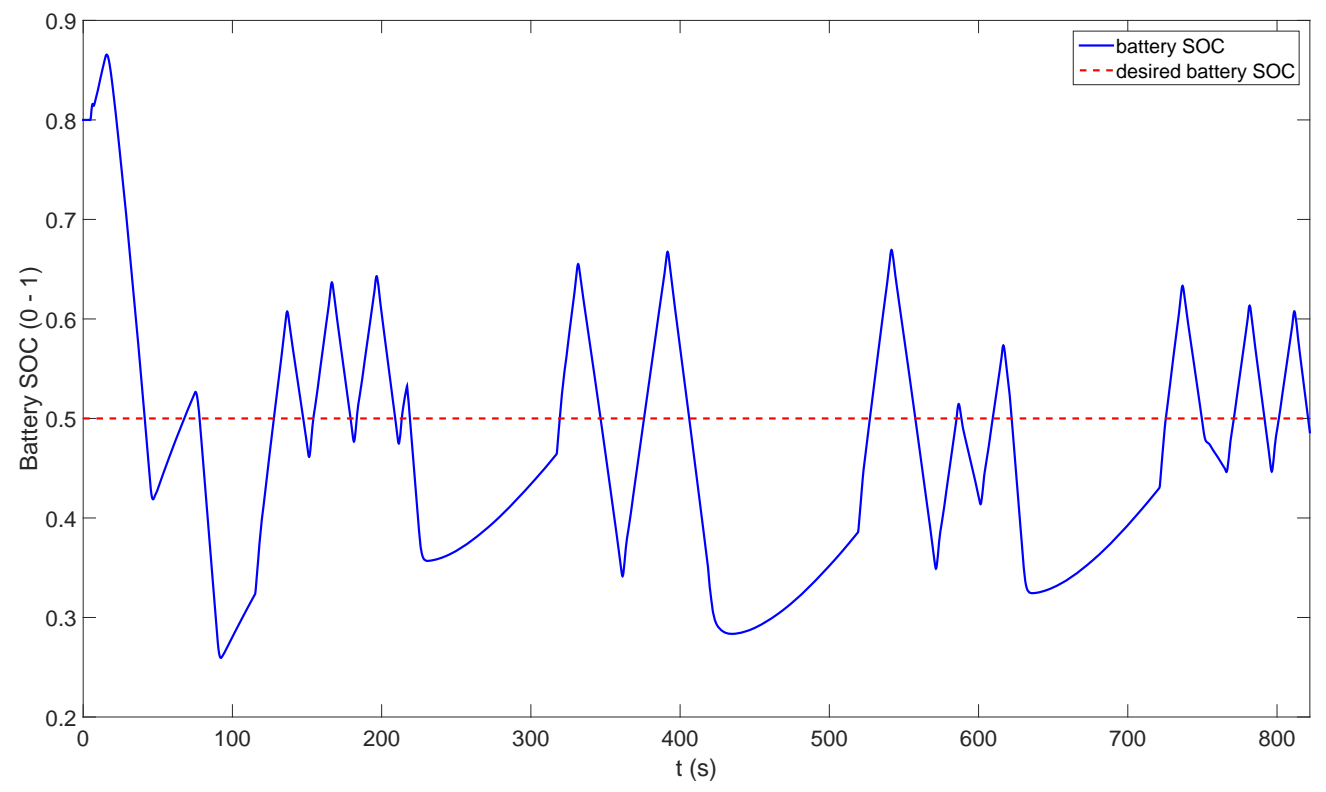

Figure 26: Battery SOC variance with SOC initial value of $80 \%$

lift $p_{\text {exh }}$, the fuel rate is increasing correspondingly. Because the embedded maps are computed from oxygen-fuel-ratio maps, the required oxygen is also increasing. Therefore, $p_{i n}^{*}$ and $W_{e g r}^{*}$ increase slightly to meet the requirements on more fresh air delivery. At the same time, $\chi_{v g t}$ moves toward close to promote $p_{\text {exh }}$. As a result, $\chi_{\text {egr }}$ decreases to compensate the increasing tendency of $W_{\text {egr }}$. The magnified results are presented in Fig. 19 to observe the tracking performances and actuator actions more clearly. The centralized decoupling controller guarantees that all the three performance variables are tracked fast and accurately, with very short settling time and minor overshooting.

The simulation results at $1800 \mathrm{rpm}, 700 \mathrm{Nm}$ have been shown in Fig. 15 and Fig. 16 in the supervisory level controller design section. In both testing conditions, the tracking performances are very desirable.

\subsubsection{Tracking Evaluation at Transients}

In the transient tests, the transient period is set as $1 \mathrm{~s}$, and the demand engine speed is fixed at $1800 \mathrm{rpm}$. The engine load switches between $260 \mathrm{Nm}$ and 700 $\mathrm{Nm}$, which is demonstrated as the left column of Fig. 20. To reduce the overshoots in transients, $\chi_{v g t}$ is allowed to vary between [0.3, 0.9]. The right column of Fig. 20 shows the performance of engine speed recovery in load acceptance. As a 
comparison, a $2 \mathrm{I} 2 \mathrm{O}$ controller is implemented on the ETDE, with the ETA being shut off. In the 2I2O control, $\chi_{v g t}$ and $\chi_{\text {egr }}$ are used to control $p_{i n}$ and $W_{\text {egr }}$, where the controller is also built from the systune solver. The engine speed recovers to the desired value $1800 \mathrm{rpm}$ much faster in the $3 \mathrm{I} 3 \mathrm{O}$ control mode, owing to that the ETA works in the motoring mode during load acceptance.

The $p_{\text {exh }}^{*}$ at low load and high load are set as $215 \mathrm{kPa}$ and $265 \mathrm{kPa}$, respectively. The tracking performances in transients are illustrated as the left column of Fig. 21. At the high load, $p_{i n}^{*}$ and $W_{e g r}^{*}$ are around $250 \mathrm{kPa}$ and $0.047 \mathrm{~kg} / \mathrm{s}$, respectively. At the low load, $p_{i n}^{*}$ and $W_{e g r}^{*}$ are around $170 \mathrm{kPa}$ and $0.026 \mathrm{~kg} / \mathrm{s}$, respectively. Small spikes are observed on $p_{i n}^{*}$ and $W_{e g r}^{*}$ when operating point changes, as they are read from look-up tables respect to $N$ and $T_{L}$ through gain scheduling. Unified promising performances are guaranteed in both steady states and transients. Only small overshoots are induced in the tracking due to the fast regulation of the centralized controller.

The corresponding actuator actions are shown as the right column of Fig. 21. When the engine operating point switches from low load to high load, $\chi_{v g t}$ closes to its lower limit, together with $P_{e m}$ works at the maximum motoring power, to offer maximum boosting. All the actuator actions converge to the steady values quickly. Only gain values rather than the system models are scheduled when operating point changes, which reduces the risk of system instability.

\subsection{Evaluation of the Two-Level Controllers}

The performance of the two-level controllers in energy management is validated under block loads, while the operating condition is shown as Fig. 22. The testing time is $822 \mathrm{~s}$, while $p_{e x h}^{*}$ is updated in real-time according to the SOC variation. Two cases are tested, in which $\mathrm{SOC}_{0}$ is set as $20 \%$ and $80 \%$, respectively. In the both cases, $\mathrm{SOC}^{*}$ is set as $50 \%$.

In the case of $\mathrm{SOC}_{0}=20 \%$, the change in battery SOC is illustrated in Fig. 23. The battery SOC converges to $\mathrm{SOC}^{*}$ fast and is attracted around it. The tracking performances are shown in Fig. 24. The desired values of all the three variables are very well tracked. The actuator actions are shown in Fig. 25. The ETA switches between the the motoring mode and the generating mode in realtime to adapt with both the transients acceleration/deceleration and the variation of battery SOC.

In the case of $\mathrm{SOC}_{0}=80 \%$, the $\mathrm{SOC}$ recovery performance is also excellent, as shown in Fig. 26. In this case, the setpoints of all the control variables are very well tracked, similar as in Fig. 24 and Fig. 25. 


\section{Conclusions}

An integrated two-level real-time energy management framework for the ETDE is proposed in this paper. The control inputs and control outputs are identified based on the control-oriented characterisation of the newly designed electrified engine. The boundaries of control variables are identified to guarantee that they are reachable within the allowed actuator action ranges. Initially, a model-based $H_{\infty}$ MIMO controller is designed with the non-smooth method. The tracking performance of the controller is shown to be fast and accurate in both transient and steady state conditions. On top of the low level MIMO controller, the supervisory level controller optimises the fuel economy in real-time. At the same time, the sustainable usage of battery is well guaranteed based on the closed-loop control of battery SOC. Since the optimal values of air system critical variables are read from look-up tables, instant distribution of the desired energy flows is achieved. The transient response is accelerated because of the ETA assistance. The effectiveness of the proposed integrated energy management framework is demonstrated with the simulation results obtained on a high fidelity physical engine model. The next step work would be the verification of the proposed energy management strategy on an experimental test bed.

\section{Acknowledgement}

This work was co-funded by Innovate UK, under a grant for the Low Carbon Vehicle IDP4 Programme (TP14/LCV/6/I/BG011L). Innovate UK is an executive body established by the United Kingdom Government to drive innovation. It promotes and invests in research, development and the exploitation of science, technology and new ideas for the benefit of business - increasing sustainable economic growth in the UK and improving quality of life.

\section{References}

[1] A. M. K. P. Taylor, Science review of internal combustion engines, Energy Policy 36 (12) (2008) 4657-4667.

[2] H. Tang, A. Pennycott, S. Akehurst, C. J. Brace, Effects of exhaust gas recycle in a downsized gasoline engine, Applied Energy 105 (2013) 99-107.

[3] A. Bin Mamat, R. Martinez-Botas, S. Rajoo, A. Romagnoli, S. Petrovic, Waste heat recovery using a novel high performance low pressure turbine 
Acronyms

\begin{tabular}{ll}
\hline Acronym & Full name \\
\hline EM & electric machine \\
ETDE & electrified turbocharged diesel engine \\
HDV & heavy duty vehicle \\
VGT & variable geometry turbine \\
EGR & exhaust gas recirculation \\
MIMO & multi-input multi-output \\
SOC & state-of-charge \\
ETA & electric turbo assist \\
SRM & switched reluctance motor \\
ECU & engine control unit \\
NRMSD & normalized root-mean-square deviation \\
NO & nitrogen oxides \\
PM & particulate matters \\
ORC & Organic Rankine Cycle \\
TEG & thermal electric generator \\
\hline
\end{tabular}

for electric turbocompounding in downsized gasoline engines: Experimental and computational analysis, Energy 90 (1) (2015) 218-234.

[4] H. Tang, A. Pennycott, S. Akehurst, C. J. Brace, A review of the application of variable geometry turbines to the downsized gasoline engine, International Journal of Engine Research 16 (6) (2015) 810-825.

[5] R. Martinez-Botas, A. Pesiridis, M. Yang, Overview of boosting options for future downsized engines, Science China Technological Sciences 54 (2) (2011) 1-14.

[6] J. Panting, K. Pullen, R. Martinez-Botas, Turbocharged motor-generator for improvement of transient performance in an internal combustion engine, Proceedings of the Institution of Mechanical Engineers Part D-Journal of Automobile Engineering 215 (3) (2001) 369-383.

[7] C. Katsanos, D. Hountalas, T. Zannis, Simulation of a heavy-duty diesel engine with electrical turbocompounding system using operating charts for turbocharger components and power turbine, Energy Conversion and Management 76 (2013) 712-724. 
[8] R. Zhao, W. Zhuge, Y. Zhang, M. Ynag, R. Martinez-Botas, Y. Yin, Study of two-stage turbine characteristic and its influence on turbo-compound engine performance, Energy Conversion and Management 95 (2015) 414-423.

[9] D. Singh, E. Pedersen, A review of waste heat recovery technologies for maritime applications, Energy Conversion and Management 111 (2016) 315328.

[10] G. Shu, Y. Liang, H. Wei, H. Tian, J. Zhao, L. Liu, A review of waste heat recovery on two-stroke IC engine aboard ships, Renewable and Sustainable Energy Reviews 19 (2013) 385-401.

[11] S. Bilgen, Structure and environmental impact of global energy consumption, Renewable and Sustainable Energy Reviews 38 (2014) 890-902.

[12] U. Hopmann, M. Algrain, Diesel engine electric turbo compound technology, SAE International (2003) 2003-01-2294.

[13] S. Arnold, C. Balis, P. Barthelet, E. Poix, T. Samad, G. Hampson, S. Shahed, Garrett electric boosting systems (EBS) program, Tech. Rep. DE-FC0500OR22809, Honeywell Turbo Technologies, Rolle, Switzerland (June 2005).

[14] S. Ibaraki, Y. Yamashita, K. Sumida, H. Ogita, Y. Jinnai, Development of the hybrid turbo, an electrically assisted turbocharger, Mitsubishi Heavy Industries Technical Review 43 (3) (2006) 1-5.

[15] I. Kolmanovsky, A. Stefanopoulous, B. Powell, Improving turbocharged diesel engine operation with turbo power assist system, in: Proceedings of the IEEE International Conference on Control Applications, 1999, pp. 454459.

[16] F. Millo, F. Mallamo, E. Pautasso, The potential of electric exhaust gas turbocharging for HD diesel engines, SAE International (2006) 2006-010437.

[17] T. Katrasnik, V. Medica, F. Trenc, Analysis of the dynamic response improvement of a turbocharged diesel engine driven alternating current generating set, Energy Conversion and Management 46 (2005) 2838-2855. 
[18] A. Grnman, P. Sallinen, J. Honkatukia, J. Backman, A. Uusitalo, Design and experiments of two-stage intercooled electrically assisted turbocharger, Energy Conversion and Management 111 (2016) 115-124.

[19] A. Costall, R. Ivanov, T. Langley, Electric turbo assist as an enabler for engine downspeeding, in: Proceedings of the ASME Turbo Expo, 2012, pp. $511-521$.

[20] A. Costall, R. Ivanov, T. Langley, Electric turbo assist: efficient rapid boost for heavy duty diesel engines, in: Proceedings of the Conference on Thermo and Fluid Dynamic Processes in Direct Injection Engines, 2012, pp. 1-18.

[21] N. Terdich, R. Martinez-Botas, D. Howey, C. Copeland, Off-road diesel engine transient response improvement by electrically assisted turbocharging, SAE International (2011) 2011-24-0127.

[22] N. Terdich, R. Martinez-Botas, Experimental efficiency characterization of an electrically assisted turbocharger, SAE International (2013) 2013-240122 .

[23] N. Terdich, R. Martinez-Botas, A. Romagnoli, A. Pesiridis, Mild hybridization via electrification of the air system: Electrically assisted and variable geometry turbocharging impact on an off-road diesel engine, Journal of Engineering for Gas Turbines and Power-Transactions of the ASME 136 (3) (2014) 031703.

[24] J. Wahlstrom, L. Eriksson, Output selection and its implications for MPC of EGR and VGT in diesel engines, IEEE Transactions on Control Systems Technology 21 (3) (2013) 932-940.

[25] M. Jankovic, I. Kolmanovsky, Constructive Lyapunov control design for turbocharged diesel engines, IEEE Transactions on Control Systems Technology 8 (2) (2000) 288-299.

[26] M. Jung, K. Glover, Calibratable linear parameter-varying control of a turbocharged diesel engine, IEEE Transactions on Control Systems Technology 14 (1) (2006) 45-62.

[27] H. Jin, S. Choi, H. Jung, Simplified multiple sliding mode transient control with VGT and EGR diesel engine, SAE International (2013) 2013-01-0345. 
[28] P. Ortner, L. del Re, Predictive control of a diesel engine air path, IEEE Transactions on Control Systems Technology 15 (3) (2007) 449-456.

[29] A. Plianos, R. K. Stobart, Nonlinear airpath control of modern diesel powertrains: a fuzzy systems approach, International Journal of Systems Science 42 (2011) 263-275.

[30] D. Zhao, R. Stobart, Systematic control on energy recovery of electrified turbocharged diesel engines, in: Proceedings of the 54th IEEE Conference on Decision and Control, 2015, pp. 1527-1532.

[31] D. Zhao, E. Winward, Z. Yang, R. Stobart, T. Steffen, Decoupling control of electrified turbocharged diesel engines, in: Proceedings of the American Control Conference, 2016, pp. 4207-4212.

[32] D. Zhao, E. Winward, Z. Yang, R. Stobart, T. Steffen, Robust control of electrified turbocharged diesel engines, in: Proceedings of the 55th IEEE Conference on Decision and Control, 2016, in press.

[33] L. del Re, F. Allgower, L. Glielmo, C. Guardiola, I. Kolmanovsky, Automotive Model Predictive Control: Models, Methods, and Applications, Springer-Verlag, Berlin, Germany, 2010.

[34] B. Glenn, D. Upadhyay, G. Washington, Control design of electrically assisted boosting systems for diesel powertrain applications, IEEE Transactions on Control Systems Technology 18 (4) (2010) 769-778.

[35] H. Zhang, E. Wang, B. Fan, M. Ouyang, S. Xia, Model-based design of a variable nozzle turbocharger controller, International Journal of Automotive Technology 12 (2) (2011) 173-182.

[36] T. Poloni, B. Rohal-Ilkiv, T. Johansen, Mass flow estimation with model bias correction for a turbocharged diesel engine, Control Engineering Practice 23 (2014) 22-31.

[37] J. Wahlstrom, L. Eriksson, L. Nielsen, EGR-VGT control and tuning for pumping work minimization and emission control, IEEE Transactions on Control Systems Technology 18 (4) (2010) 993-1003.

[38] P. Apkarian, D. Noll, Nonsmooth $H_{\infty}$ synthesis, IEEE Transactions on Automatic Control 51 (1) (2006) 71-86. 
[39] P. Apkarian, D. Noll, Optimization-based control design techniques and tools, in: J. Baillieul, T. Samad (Eds.), Encyclopedia of Systems and Control, Springer London, 2014, pp. 1-12. 